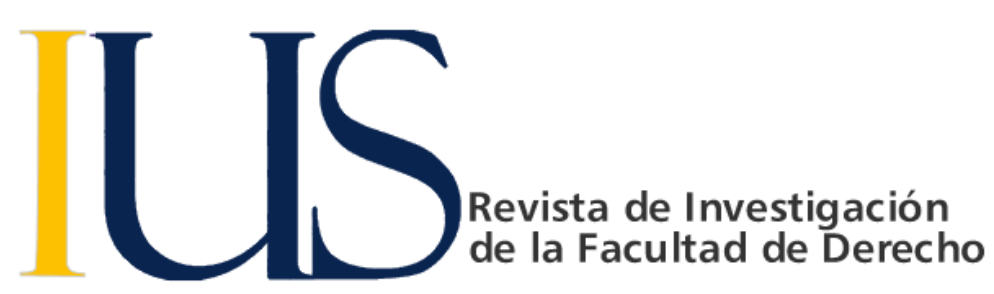

\title{
DEL ACTIVISMO A LA DEMIURGIA JUDICIAL: ¿CUÁL ES EL VALOR REAL DE UN TRATADO INTERNACIONAL DE DERECHOS HUMANOS? José Luis Bazán ${ }^{1}$
}

\begin{tabular}{ll}
\hline INFORMACIÓN DEL ARTÍCULO & RESUMEN \\
\hline Historia del artículo: & La práctica, cada vez más extendida en los tribunales internacionales de \\
Recibido el 10 de junio de 2019 & derechos humanos, de superar la letra y el espíritu de los tratados \\
Aceptado el 03 de octubre de 2019 & internacionales que han de interpretar, y de reconfigurar unilateralmente su \\
\hline Palabras clave: & contenido obligacional sin respetar los procedimientos previstos de reforma, \\
Derechos humanos & está modificando sustancialmente el derecho internacional de los derechos \\
activismo & humanos. La interpretación se convierte, de este modo, en una práctica \\
tribunal internacional & demiúrgica que crea ex novo y sin fundamento legal nuevos derechos (o \\
& incluso, pretendidos e inexistentes "derechos") que no sólo no se contienen en \\
& los tratados, sino que, en no pocos casos, pueden minar seriamente el \\
& contenido sustancial de derechos explícita y generalmente reconocidos como \\
& fundamentales. La incertidumbre jurídica y los altos riesgos de interpretación \\
& ideológica y arbitraria de los derechos que genera este activismo judicial se \\
& añaden a la vulneración de principios tan básicos como el consentimiento del \\
& Estado Parte como fuente de obligaciones internacionales convencionales. La \\
& integridad de los derechos humanos exige que los tribunales internacionales \\
& abandonen tales prácticas arbitrarias, respeten los límites de su mandato \\
& interpretativo otorgado y dejen de operar de facto y abusivamente como \\
& órganos legisladores
\end{tabular}

From activism to judicial demiurgy: what is the real value of an international human rights treaty?

\section{ABSTRACT}

\section{Keywords:}

Human rigths

activism

international court

The practice, increasingly widespread in international human rights courts, of overcoming the letter and spirit of the international treaties to be interpreted, and of unilaterally reconfiguring its mandatory content without respecting the planned reform procedures, is substantially modifying the International Law of human rights. The interpretation thus becomes a demiurgic practice that creates ex-de novo and without legal basis new rights (or even pretended and non-existent "rights") that not only are not contained in the treaties, but, in not a few cases, they can seriously undermine the substantial content of explicit rights and generally recognized as fundamental. The legal uncertainty and the high risks of ideological and arbitrary interpretation of the rights generated by this judicial activism are added to the violation of such basic principles as the

\footnotetext{
${ }^{1}$ Profesor Asociado de Derechos y Libertades Públicas de la Universidad Internacional de La Rioja, España. Contacto: hispanialex@yahoo.es ,
} ORCID: $0000-0002-7617-2648$ 
consent of the State party as a source of conventional international obligations. The integrity of human rights requires that international tribunals abandon such arbitrary practices, respect the limits of their interpretative mandate granted and cease to operate de facto and abusively as legislative bodies.

\section{Introducción}

El activismo judicial en materia de derechos humanos, que desde hace décadas se ha implantado en altos tribunales de algunos países, ${ }^{2}$ ha irrumpido con fuerza en el ámbito internacional, en particular en el Tribunal Europeo de Derechos Humanos (TEDH). Aunque son diversas las definiciones propuestas por distintos autores, ${ }^{3}$ por activismo judicial entendemos la actitud de los jueces que conforman un tribunal, ordinariamente de orden superior, que en su actividad interpretativa adoptan decisiones que no aplican o contradicen los mandatos de las normas y reglas jurídicas que han de interpretar y aplicar, elaboradas por quien tiene potestad legislativa, basándose en una visión y ponderación personal de los valores y principios que deberían impregnar y orientar la sociedad. ${ }^{4} \mathrm{El}$ activismo judicial tuvo su origen en la actitud del Tribunal Supremo norteamericano en los años 30 frente a las decisiones de política económica del gobierno norteamericano, aunque según Kmiec, fue Arthur Schlesinger Jr. quien primero usó el término en enero de 1947 en su artículo titulado The Supreme Court en la revista Fortune, para referirse a los jueces Black, Douglas, Murphy y Rutledge frente a los representantes del "judicial self-restraint" encarnado en los jueces Frankfurter, Jackson y Burton. ${ }^{5} \mathrm{El}$ "judicial activism" tuvo su nueva época dorada en Estados Unidos durante los años 50 y 60, en el contexto de las tensiones sociales y el debate público sobre los derechos civiles. ${ }^{6}$ Pero en los últimos años, de nuevo, la cuestión está fuertemente presente en el Tribunal Supremo de EE.UU en relación con temas como la sodomía homosexual, ${ }^{7}$ el "matrimonio" entre personas del mismo $\operatorname{sexo}^{8}$ o la objeción de conciencia frente al mandato de proveer contraceptivos. ${ }^{9}$ Sin embargo, esta actitud judicial de orientación meta-normativa se ha expandido con fuerza en otras tantas jurisdicciones nacionales (en particular en las más altas instancias), y ha saltado a las jurisdicciones internacionales de derechos humanos.

En el análisis del activismo judicial en el presente trabajo nos centraremos en la experiencia jurisprudencial del Tribunal Europeo de Derechos Humanos (también llamado Tribunal de Estrasburgo), en el contexto de las reglas generales de interpretación de los tratados internacionales, y en particular, del Convenio Europeo de Derechos Humanos (CEDH) y sus Protocolos Adicionales. A través de la doctrina de la "autonomía de

2 CASTAÑO PEÑA, Jairo Andrés, "Análisis económico del activismo judicial: el caso de la Corte Constitucional colombiana", Revista Derecho del Estado, núm. 31, julio-diciembre, Bogotá, 2013, pp. 119-160: http://bit.ly/1VTs3yp. CHOUDHRY, Sujit y HUNTER, Claire E., "Measuring Judicial Activism on the Court of Canada: A Comment on Newfoundland (Treasury Board) v. NAPE", McGill Law Journal, 2003, vol. 48, pp. 525-562: http://bit.ly/22tmOkd. LOPEMAN, Charles S., The Activist Advocate: Policy Making in State Supreme Courts, Greenwood, 1999. RUIZ SOROA, José María, “¿Reglas o principios?", El País, 8 julio 2013: http://bit.ly/1Mvu2XX.

3 La definición de Hellman, basada en la del Juez Richard Posner: "decisiones que expanden el poder judicial sobre las instituciones políticas" HELLMAN, Arthur D., "Judicial Activism: The Good, the Bad, and the Ugly", Mississippi College Law Review, Vol. 21, 2002, p. 253: http://bit.ly/1V1uaBc.

${ }^{4}$ La distinción entre reglas (normativas) y estándares (de razonabilidad) como parámetros centrales de interpretación judicial que pueden corresponderse con el "judicial self-restraint" y el "judicial activism", respectivamente, no explica suficientemente el núcleo del activismo judicial, que está vinculado al propósito ideológico de transformación de la orientación ética de la sociedad. Vid. CALABRESI, Steven G. y LAWSON, Gary, "The Rule of Law as Law of Law", Notre Dame Law Review, Vol. 90, no 2, 2014, pp. 483-504: http://ntrda.me/109rwkW.

5 KMIEC, Keenan D., "The Origin and Current Meanings of Judicial Activism", California Law Review vol. 92, no 5, octubre 2004, p. 1.446: http://bit.ly/1qoJllE. BARRETT, John Q., Arthur M. Schlesinger, Jr. - in Action, in Archives, in History, 2007: http://bit.ly/1V1sdF0. MAYER, David N., Liberty of Contract: Rediscovering a Lost Constitutional Right, Cato Institute, Washington, 2011, p. 151.

${ }^{6}$ En temas como contracepción (Griswold v. Connecticut, 381 U.S. 479, sentencia de 7 de junio de 1965: http://bit.ly/1GPiwhH) o aborto (Roe v. Wade, 410 U.S. 113, sentencia de 22 de enero de 1973: http://bit.ly/1h5nErz). Pero también sobre discriminación racial (Brown v. Board of Education of Topeka, No. 1., sentencia de 17 de mayo de 1954: http://bit.ly/22wB40r). Vid. LOPEMAN, Charles S., The Activist Advocate: Policy Making in State Supreme Courts, Greenwood, 1999, p. 3; COVER, Robert M., "The Origins of Judicial Activism in the Protection of Minorities", The Yale Law Journal, Vol. 91, no 7, junio 1982: http://bit.ly/109oHAu.

7 Lawrence v. Texas, 539 U.S. 558, sentencia de 26 de junio de 2003: http://bit.ly/1qr3LzM.

8 Obergefell v. Hodges, 26 de junio de 2015: http://bit.ly/1MFsGE3.

${ }^{9}$ Numerosos casos consolidados están pendientes de resolución en el Tribunal Supremo norteamericano sobre este asunto: Zubik v. Burwell (http://bit.ly/1RUdMxm), Roman Catholic Archbishop of Washington v. Burwell (http://bit.ly/1Sc43Ee), Priests for Life v. Burwell (http://bit.ly/1Sc4370), Little Sisters of the Poor Home for the Aged v. Burwell (http://bit.ly/1PjSX0w), East Texas Baptist University v. Burwell (http://bit.ly/1RVyU9f), Southern Nazarene University v. Burwell (http://bit.ly/1MvEW05) y Geneva College v. Burwell (http://bit.ly/1qJmh75). 
los términos del Convenio", el órgano judicial europeo ha realizado un ajuste entre la estandarización en ciertas áreas de derechos humanos y el margen de apreciación de los Estados. Si bien la estandarización suele sancionarla judicialmente apelando al "consenso europeo", lo cierto es que en numerosas ocasiones el Tribunal Europeo ha dado muestras de un preocupante activismo judicial en áreas de altísima sensibilidad ética, como la regulación legal del aborto o la explotación reproductiva (nombrada con diversidad de expresiones como: "alquiler de úteros", "maternidad subrogada", etc.). Tal activismo judicial ha tomado una fuerza expansiva de tal calibre que los Estados Partes sometidos a su jurisdicción (los 47 Estados miembros del Consejo de Europa) que han iniciado una reforma del sistema de protección de los derechos humanos de Estrasburgo, incluyendo una explícita clarificación de la naturaleza internacional (y no supranacional) del Tribunal $-y$, por tanto, subsidiaria de las jurisdicciones nacionales-. Se le exige al órgano judicial igualmente, una aplicación rigurosa y consistente de los criterios de admisibilidad y jurisdicción. Esta actitud de los Estados es expresión de una comprensión general de que el Tribunal se ha excedido frecuentemente en sus potestades y funciones auto-atribuyéndose indebidamente la condición de cuarta instancia europea, ${ }_{10}^{10}$ por encima, incluso de tribunales supremos y constitucionales nacionales. ${ }^{11}$

\section{ESPECIFICIDAD DE LOS TRATADOS INTERNACIONALES DE DERECHOS HUMANOS}

${ }^{10} \mathrm{El}$ Tribunal Europeo reconoce en su jurisprudencia que "no es su función decidir sobre los errores de hecho o derecho presuntamente cometidos por un tribunal nacional salvo que estos hayan podido vulnerar derechos y libertades protegidos por el Convenio" (García Ruiz vs. España, sentencia de 21 de enero de 1999, ap. 28; en idéntico sentido, Perez vs. Francia, Gran Sala, sentencia de 12 de febrero de 2004, ap. 82).

11 COUNCIL OF EUROPE, Reforming the European Convention on Human Rights. Interlaken, Izmir, Brighton and Beyond. A compilation of instruments and texts relating to the ongoing reform of the ECHR, Strasbourg, 2014: http://bit.ly/1qJdcek. DAHLBERG, M., "'...It is not its task to act as a Court of fourth instance:' the case of the European Court of Human Rights", European Journal of Legal Studies, vol. 7 no 2, 2014, pp. 84-118: http://bit.ly/1Shhd65.

12 NACIONES UNIDAS, Definiciones de términos fundamentales en la Colección de Tratados de las Naciones Unidas, 2011: http://bit.ly/1Mtiglb.

${ }^{13}$ Chipre vs. Turquía, Gran Sala, sentencia de 12 de mayo de 2014, $\S 23$.

${ }^{14}$ BERNHARDT, R., "Thoughts on the interpretation of human-rights treaties", en: MATSCHER, F. y PETZOLD, H., Protecting Human Rights: The European Dimension. Studies in Honour of Gérard J. Wiarda, Colonia, 1988, pp. 70-71.

15 En relación con la posibilidad de denuncia del Pacto de Derechos Civiles y Políticos de 1966, el Comité de Derechos Humanos de
La expresión "tratado internacional de derechos humanos" engloba todo instrumento internacional de derechos humanos que genera obligaciones jurídicas a las Partes contratantes, con independencia del concreto nombre que se le asigne, según lo establecido por los Convenios de Viena de Derecho de Tratados de 1969 y 1986 (Artículos 31 a 33) ${ }^{12}$. Estos Convenios recogen también las reglas generales de interpretación de tratados internacionales, que son aplicables, en principio, a los tratados de derechos humanos, ${ }^{13}$ aunque el objeto y propósito de éstos difieren de los del resto de tratados, lo que origina ciertas reglas específicas de interpretación: ${ }^{14}$ por ejemplo, en lo relativo a las reservas o su denuncia; ${ }^{15}$ o la no aplicabilidad del principio de reciprocidad ex Artículo 21.1 del Convenio de Viena de $1969^{16}$.

Es cierto, como afirma el juez Cançado Trindade, que la interpretación de los tratados de derechos humanos suele enfatizar su objeto y fines sobre otras consideraciones, dado que las obligaciones asumidas por los Estados que los ratifican son esencialmente objetivas y no subjetivas, recíprocas o inter-partes. ${ }^{17}$ Igualmente cierto es que tales tratados no son considerados objeto de irrestricto sometimiento a la libérrima voluntad de los Estados Parte una vez que han asumido las obligaciones derivadas de aquéllos, como lo confirma la jurisprudencia del TEDH. Por el contrario, más bien se enfatiza la necesidad de la protección práctica y efectiva de los derechos humanos reconocidos, ${ }^{18}$ y una interpretación restrictiva de sus limitaciones $^{19}$. En realidad, tales consideraciones que

Naciones Unidas, en su Observación General no 26 afirma que no existe tal, entre otras cosas, porque por su naturaleza dicho tratado no tiene un carácter temporal, típico de los tratados en los que se reconoce el derecho a denunciarlos incluso cuando no existe previsión explícita al respecto. Sobre los límites a las reservas en los tratados de derechos humanos, vid. Comité de Derechos Humanos de Naciones Unidas, Observación General no 24, 11 de noviembre de 1994, ap. 8 ss.

16 Decisión sobre la admisibilidad de la demanda, caso Francia, Noruega, Dinamarca, Suecia, Países Bajos vs. Turquía, 6 de diciembre de 1983, ap. 39.

17 Corte Interamericana de Derechos Humanos, sentencia en el caso Caesar versus Trinidad y Tobago, de 11 de marzo de 2005 (Fondo, Reparaciones y Costas), voto particular concurrente, ap. 5.

${ }^{18}$ Como afirma el Tribunal Europeo de Derechos Humanos: "Debe recordarse que el Convenio no busca la garantía teórica o ilusoria de los derechos, sino su protección práctica y efectiva." (Waite y Kennedy vs. Alemania, sentencia de 18 de febrero de 1999, §67).

19 Art. 18 CEDH: "Las restricciones que, en los términos del presente Convenio, se impongan a los citados derechos y libertades no podrán ser aplicadas más que con la finalidad para la cual hayan sido previstas." Además, las limitaciones a un derecho del CEDH no deben implicar una restricción o reducción tal que comprometa su propia esencia: vid. Osman vs. Reino Unido, sentencia de 28 de octubre de 1998, §147. Es más, hay ciertos derechos que son 
trascienden la intersubjetividad estatal de los Estados Parte apuntan a la tesis de los tratados de derechos humanos como generadores de un ordre publique, aunque sea limitadamente, que conlleva un deber de ejercicio de la garantía colectiva de tales derechos. Se trata, pues, de un sistema colectivo de tutela de derechos humanos: así, la Comisión Europea de Derechos Humanos recordó en el caso Francia, Noruega, Dinamarca, Suecia, Países Bajos vs. Turquía que "el Convenio se funda sobre el sistema de 'garantía colectiva de las Altas Partes Contratantes de los derechos y libertades reconocidos en el Convenio", y que, por ello, al presentar una demanda contra otro Estado ex Artículo $33 \mathrm{CEDH}$ tal acto del Estado demandante "no debe verse como el ejercicio de un derecho o acción con el propósito de garantizar sus propios derechos, sino más bien como la presentación ante la Comisión de una violación alegada del orden público de Europa". ${ }^{20} \mathrm{Al}$ concluir el CEDH, sostiene la Comisión Europea de Derechos Humanos, el propósito de las Altas Partes contratantes "no era conceder a las demás derechos y obligaciones recíprocos según sus intereses nacionales individuales sino cumplir los objetivos e ideales del Consejo de Europa, como se expresa en su Estatuto, y establecer un orden público común de las democracias libres de Europa, con el objeto de salvaguardar su herencia común de tradiciones políticas, ideales, libertad e imperio del derecho." ${ }^{21}$ De ahí, por ejemplo, que el TEDH haya deducido del carácter colectivo de la garantía de los derechos humanos del CEDH el deber de los Estados Contratantes, bajo ciertas circunstancias, "de actuar conjuntamente y colaborar para la protección de los derechos y libertades que se han comprometido a asegurar bajo su jurisdicción". ${ }^{22}$ Por este motivo, se considera que las demandas interestatales en el sistema europeo no tienen como finalidad la auto-tutela del Estado demandante y sus derechos, sino la protección de las personas bajo la jurisdicción del Estado

absolutos, inderogables y no pueden ser objeto de limitación, como la prohibición de tortura ex Art. $3 \mathrm{CEDH}$ : "El Artículo 3 no prevé ninguna excepción y no cabe su derogación bajo el Art. 15 del Convenio, incluso en caso de emergencia pública que amenace la vida de la nación." (Saadi vs. Italia, sentencia de 28 de febrero de 2008, §127).

${ }^{20}$ Decisión sobre la admisibilidad de la demanda, Francia, Noruega, Dinamarca, Suecia, Países Bajos vs. Turquía, 6 de diciembre de 1983, §40.

${ }^{21}$ Decisión sobre la admisibilidad de la demanda, Austria vs. Italia, 11 de enero de 1961, p. 18.

22 Güzelyurtlu y Otros vs. Chipre y Turquía, Gran Sala, sentencia de 29 de enero de 2019, §232.

23 Vid.: European Court of Human Rights, Practical Guide on Admissibility Criteria, updated on 31 August 2019, p. 17. Sobre la demandado, que sean "víctimas", en el sentido del Convenio ex Artículo 34, de la violación alguno de sus derechos garantizados por este tratado internacional, un derecho al recurso ante el Tribunal que ha sido considerado absoluto ${ }^{23}$. No en vano, la función primaria del TEDH es, como sostiene McCrudden, "tratar de asegurar que el individuo en particular no padece la opresión del Estado" 24 mediante el sistema de demandas de individuos contra Estados.

El TEDH ha ido aún más allá en su jurisprudencia al afirmar la naturaleza del CEDH como "instrumento constitucional del orden público europeo" en materia de derechos humanos." 25 La consideración del Convenio como una norma de naturaleza constitucional introduce elementos perturbadores difícilmente conciliables con el propósito perseguido por los Estados Partes al ratificar o acceder al CEDH, que no era la integración jurídica en materia de derechos humanos, sino, como afirma su Preámbulo "tomar las primeras medidas adecuadas para asegurar la garantía colectiva de algunos de los derechos enunciados en la Declaración Universal". Garantía colectiva no significa protección uniforme, como sería el caso en un sistema de integración al modo de la actual Unión Europea: el Consejo de Europa opera sobre la base de la cooperación entre sus Estados miembros (algo que se debe proyectar también sobre el Tribunal de Estrasburgo como su órgano judicial), y no tiene como misión profundizar en la integración entre ellos. Al respecto es clara la dicción del Tratado de la Unión Europea, cuyo preámbulo en dos párrafos distintos afirma que los Estados firmantes están resueltos "a salvar una nueva etapa en el proceso de integración europea emprendido con la constitución de las Comunidades Europeas" (...) "ante la perspectiva de las ulteriores etapas que habrá que salvar para avanzar en la vía de la integración europea" ${ }^{26}$ La distinción entre sistemas cooperativos y de integración es importante para prevenir que el TEDH se convierta (o, al menos,

noción de "derecho absoluto", vid. MAVRONICOLA, Natasa, "What is an 'absolute right'? Deciphering Absoluteness in the Context of Article 3 of the European Convention on Human Rights", Human Rights Law Review vol. 12, 4, 2012, pp. 723-758.

24 McCRUDDEN, Christopher, "Using Comparative Reasoning in Human Rights Adjudication: The Court of Justice of the European Union and the European Court of Human Rights Compared", 15 (2012-13), Cambridge Yearbook of European Legal Studies vol. 15, 2012-2013, Hart Publishing, 2013, p. 406.

25 Loizidou vs. Turquía (objeciones preliminares), sentencia de 23 de marzo de 1995, §75: http://bit.ly/26598pd; Bosphorus Hava Yolları Turizm ve Ticaret Anonim Şirketi vs. Irlanda, Gran Sala, sentencia de 30 de junio de 2005, §156: http://bit.ly/1W2kg1e.

${ }^{26}$ Versión consolidada, DOUE 2012/C 326/01, de 26 de octubre de 2012: http://bit.ly/1V5VluH. 
pretenda convertirse) en una instancia constitucional al afirmar la naturaleza constitucional del texto que tiene encomendado aplicar

\section{AUTONOMÍA DE LOS TÉRMINOS DEL TRATADO}

Algunas nociones relacionadas con los derechos humanos contenidas en los tratados internacionales poseen un significado internacional autónomo, que en caso de ausencia de explícita definición, debe ser perfilado según el propósito y estructura del tratado, y un objetivo, imparcial y completo análisis de la situación jurídica y las tradiciones constitucionales de los Estados Parte en él. ${ }^{27}$ En el ámbito de Naciones Unidas, podemos mencionar como ejemplo de interpretación autónoma de los términos de un tratado, la palabra "home" del Artículo 17 del Pacto de Derechos Civiles y Políticos, de 1966 ("domicilio" en español; "manzel" en árabe, "zhùzhái" en chino, "domicile" en francés, "zhilishche" en ruso), cuyo significado no depende de los derechos domésticos de las Partes Contratantes -por otro lado, tan diferentes-, sino que debe entenderse como el "lugar donde una persona reside o ejerce su ocupación habitual". ${ }^{28}$

En el TEDH este procedimiento también es comúnmente utilizado. Así, por ejemplo, el Artículo 6.1 CEDH garantiza el derecho de todo individuo a llevar ante un tribunal lo relativo a "sus derechos y obligaciones de carácter civil (...)". Cuáles sean tales "derechos y obligaciones civiles" es algo definido autónomamente a nivel europeo por el TEDH "en función de su contenido sustantivo y los efectos del derecho -y no su clasificación legal- de acuerdo con el

27 Este recurso hermenéutico no es exclusivo de los tratados de derechos humanos: así, el Tribunal de Justicia de las Comunidades Europeas sostuvo que se debían tener en cuenta "primero, los objetivos y estructura del Convenio, y en segundo lugar, los principios generales que se desprenden de conjunto de los sistemas jurídicos nacionales" a la hora de interpretar la expresión "materia civil y mercantil" del Convenio de Bruselas de 1968 relativo a la competencia judicial, el reconocimiento y la ejecución de resoluciones judiciales en materia civil y mercantil. LTU Lufttransportunternehmen $\mathrm{GmbH} \&$ Co. KG $\mathrm{v}$ Eurocontrol, fundamento jurídico 3.

28 COMITÉ DE DERECHOS HUMANOS DE NACIONES UNIDAS, Comentario General no 16 sobre el derecho a la intimidad (Artículo 17), 1988, ap. 5.

${ }^{29}$ König vs. Alemania, Pleno, $\$ 89$.

30 Ferrazini vs. Italia, Gran Sala, §24.

${ }^{31}$ LTU Lufttransportunternehmen GmbH \& Co. KG v Eurocontrol, fundamento jurídico 3 . En igual sentido (búsqueda de la interpretación independiente y uniforme del derecho comunitario europeo), vid.: Tribunal de Primera Instancia de las Comunidades Europeas, Anna Herrero Romeu v Commission of the European Communities, caso T-298/02, sentencia de 25 de octubre de 2005, ap. 27 (concepto de "residencia habitual"); Tribunal de Justicia, Staatssecretaris van Financiën v J.H.M. Feron, caso C-170/03, derecho sustantivo del Estado demandado, [teniendo en cuenta también] el objeto y propósito del Convenio y de los sistemas jurídicos nacionales de otros Estados Parte". ${ }^{29}$ Tal concepto no se delimita, por tanto, por referencia exclusiva a su significado y alcance en el derecho interno del Estado demandado, porque otra solución llevaría "a resultados incompatibles con el objeto y propósito del Convenio". ${ }^{30}$ Algo similar ocurre en el Derecho de la Unión Europea, donde tal método asegura, como sostiene el Tribunal de Justicia de las Comunidades Europeas, "en la medida de lo posible, que los derechos y obligaciones que derivan del Convenio para los Estados Contratantes y las personas a las que se les aplica sean iguales y uniformes" ${ }^{31}$

Así, el TEDH ha amparado ex Artículo 6.1 CEDH derechos de particulares que en algunos foros se sustanciarían en las jurisdicciones administrativas o sociales y no civiles. ${ }^{32}$ Otro ejemplo de concepto con significado autónomo en el CEDH sería el de "posesiones" (Artículo 1 del Protocolo I), que incluiría bienes físicos y no físicos, derechos actuales y expectativas legítimas y razonables de obtener un derecho de propiedad efectivo, aunque en determinados casos el derecho interno de un Estado Parte "no reconozca un interés particular como 'derecho' o incluso como 'derecho de propiedad'". ${ }^{33}$ La noción de "pena" en el Artículo 7.1 CEDH ${ }^{34}$ es considerada autónoma por el TEDH "para que la protección ofrecida por el Artículo 7 sea efectiva", lo que le obliga a "permanecer libre para enfrentarse a las apariencias y evaluar por sí mismo si una medida determinada equivale en esencia a una 'pena' en el

sentencia de 17 de marzo de 2005 (noción de "propiedad personal" y "posesión"); Tribunal de Justicia, Gran Sala, Oliver Brüstle v Greenpeace eV, caso C-34/10, sentencia de 18 de octubre de 2011, aps. 26 ss (concepto de "embrión humano"); Tribunal de Justicia, J. McB. vs. L. E., caso C-400/10 PPU, sentencia de 5 de octubre de 2010, ap. 41 (concepto de "derechos de custodia").

32 Incluye, entre otros: los procedimiento de expropiación, decisiones de planificación, permisos de construcción, y en general, decisiones que constituyen injerencia en el uso y disfrute de la propiedad; procedimientos de concesión de licencias, permisos y otro acto del poder público que es condición para celebrar un contrato entre particulares; la concesión o revocación de licencias por el poder público para desarrollar ciertas actividades económicas; suspensión o revocación de licencia para practicar determinadas profesiones; daños en procedimientos administrativos; contribuciones al sistema público de seguridad social; y cuestiones de empleo en organismos públicos en ciertos supuestos. Vid. voto particular disidente del juez Lorenzen, en la sentencia Ferrazini vs. Italia, Gran Sala, §4.

33 Depalle vs. Francia, Gran Sala, sentencia de 29 de marzo de 2010, $\S 62 s s$.

34 "No podrá ser impuesta una pena más grave que la aplicable en el momento en que la infracción haya sido cometida". 
sentido de esta disposición". ${ }^{35}$ También el concepto de "ley" que aparece en diversas disposiciones del CEDH se considera autónomo, en la medida, además, en que en el sistema del Convenio conviven tradiciones jurídicas distintas, particularmente la de derecho codificado, y la de common-law, por lo que "ley" incluye tanto el derecho escrito creado por el poder legislativo o ejecutivo como el case-law o derecho creado por los jueces, exigiéndose que las normas sean accesibles y previsibles. ${ }^{36}$ En la amplia lista de términos autónomos también figuran: la noción de "expulsión" del Artículo 1 del Protocolo $\mathrm{VII}^{37}$ que incluiría, salvo la extradición, "toda medida que obligue a la salida del extranjero del territorio donde se encuentra residiendo legalmente"; $; 8$ la de "domicilio" ex Artículo 8.1 CEDH, ${ }^{39}$ que no depende de la clasificación del derecho interno, sino de "circunstancias fácticas, en particular la existencia de vínculos suficientes y continuos con un lugar concreto", ${ }^{40}$ que ha de ser su domicilio actual; ${ }^{41}$ la de "enajenado" 42 , que el TEDH interpreta restrictivamente para incluir solo los casos de enfermos mentales de cierta gravedad que precisan tratamiento hospitalario o han de ser internados en clínica o institución apropiada; ${ }^{43}$ el concepto de "infracción penal" ${ }^{44}$ que se establece autónomamente teniendo en cuenta tres criterios (clasificación del procedimiento en el derecho intento; su naturaleza esencial y tipo y severidad de la sanción prevista) y no se limita a los procesos penales en curso, incluyendo los archivados o los casos de absolución; ${ }^{45}$ y el de "víctima" ex Artículo 34 CEDH, que incluye los familiares de víctima directa fallecida cuando su demanda se refiere a una cuestión de interés general sobre el respeto a los derechos humanos (Artículo 37.1 in fine (EDH), y también a sus herederos en cuanto poseen un legítimo interés, o sobre la base del efecto directo sobre los derechos del propio demandante cuando la víctima directa -aún viva- participaba en la

\footnotetext{
35 Del Río Prada vs. España, Gran Sala, sentencia de 21 de octubre de 2013, §81.

${ }^{36}$ E. K. vs. Turquía, sentencia de 7 de febrero de 2002, $\S 51$.

37 "Un extranjero que resida legalmente en el territorio de un Estado no podrá ser expulsado sino en ejecución de una decisión dictada conforme a la ley..."

38 Bolat vs. Rusia, sentencia de 5 de octubre de 2006, §79.

39 "Toda persona tiene derecho al respeto de su domicilio".

40 Globa vs. Ucrania, sentencia de 5 de julio de 2012, §37.

41 Decisiones sobre la admisibilidad de las demandas, caso Strunjak y otros vs. Croacia, 5 de octubre de 2000, §3; y caso Akimova vs. Azerbaiyán, 12 de enero de 2006, §3.

42 Artículo 5.1e) CEDH: privación de libertad a enajenado

43 Glien vs. Alemania, 28 de noviembre de 2013, §§83-85.
}

demanda presentada en la jurisdicción interna del Estado demandado ${ }^{46}$.

El método seguido para el establecimiento de un contenido semántico común europeo de un término del CEDH cuando existe una diversidad entre los Estados Parte, combina el recurso al examen de la situación jurídica y a las tradiciones constitucionales de los Estados parte. Es lo que el juez Mastcher llama el "'denominador común' tras las disposiciones en cuestión, ya que es legítimo suponer -en ausencia de definición legal en el mismo Convenio- que tal es el significado que los Estados Parte quisieron dar a tales disposiciones. Este 'denominador común' puede ser encontrado mediante el análisis comparativo del derecho interno de los Estados Contratantes." 47 Además de la comparativa del derecho interno de los Estados Parte, por igual motivo, deberían tenerse en cuenta en la interpretación de una expresión de un tratado internacional, otros instrumentos internacionales a los que los Estados Parte también hayan prestado su consentimiento (y por supuesto, el derecho internacional imperativo). Este punto de vista lo adoptó el Tribunal de Luxemburgo, al sostener que en materia de derechos fundamentales (en cuanto principios generales del derecho comunitario, antes de la aprobación de la Carta Europea de Derechos Fundamentales de 2010, CDF), sus fuentes de inspiración eran las derivadas de las "tradiciones constitucionales comunes a los Estados miembros, así como en las indicaciones proporcionadas por los instrumentos internacionales relativos a la protección de los derechos humanos en los que los Estados miembros han cooperado o a los que se han adherido." 48 Este principio fue plasmado en la citada CDF cuyo Preámbulo "reafirma (...) los derechos que emanan, en particular, de las tradiciones constitucionales y las obligaciones internacionales comunes a los Estados miembros, del Convenio

\footnotetext{
${ }^{44}$ Artículo 6.2 CEDH: "Toda persona acusada de una infracción penal se presume inocente hasta que su culpabilidad haya sido legalmente declarada".

45 Hammern vs. Noruega, 11 de febrero de 2003, §41.

${ }^{46}$ Centre for Legal Resources on behalf of Valentin Câmpeanu vs. Rumania, Gran Sala, sentencia de 17 de julio de 2014, §98.

47 Voto particular disidente en la sentencia König vs. Alemania, Pleno.

48 Tribunal de Justicia (Gran Sala), Ordre des barreaux francophones et germanophone y otros vs Conseil des ministres, caso C-305/05, sentencia de 26 de junio de 2007, ap. 29. En igual sentido, Tribunal de Justicia (Gran Sala), Yassin Abdullah Kadi and Al Barakaat International Foundation $v$ Council of the European Union and Commission of the European Communities, casos acumulados C402/05 P and C-415/05 P, sentencia de 3 de septiembre de 2008, ap. 283.
} 
Europeo para la Protección de los Derechos Humanos y de las Libertades Fundamentales, las Cartas Sociales adoptadas por la Unión y por el Consejo de Europa, así como de la jurisprudencia del Tribunal de Justicia de la Unión Europea y del Tribunal Europeo de Derechos Humanos." Y, sobre todo, en el Artículo 52.4 de la CDF, según el cual: "En la medida en que la presente Carta reconozca derechos fundamentales resultantes de las tradiciones constitucionales comunes a los Estados miembros, dichos derechos se interpretarán en armonía con las citadas tradiciones".

\section{EL MARGEN DE APRECIACIÓN DE LOS ESTADOS}

En caso de que existan diferencias y divergencias entre los Estados Parte en el tratado de derechos humanos, sostiene Bernhardt, debe reconocerse a los Estados un "margen de apreciación" nacional. La expresión "margen de apreciación" no aparece ni el texto del CEDH ni en sus trabajos preparatorios, siendo usada por primera vez en 1958 por la Comisión Europea de Derechos Humanos en el caso de Grecia vs. Reino Unido sobre violaciones de derechos humanos en Chipre. ${ }^{49} \mathrm{El}$ TEDH lo ha usado con frecuencia, en casos como Handyside vs. Reino Unido en relación con el concepto de "moral", al afirmar que: "no es posible encontrar en el derecho interno de los Estados miembros una concepción uniforme de la moral. El punto de vista adoptado por sus respectivos derechos sobre las exigencias de la moral varía según el momento y el lugar (...) Por razón de su contacto continuo y directo con las fuerzas vitales de sus países, las autoridades del Estado están en principio en mejor posición que el juez internacional para dar una opinión sobre el contenido exacto de tales exigencias (....)". ${ }^{50}$ Tal margen de apreciación tiene su base en el carácter subsidiario de los sistemas internacionales de derechos humanos. En el caso del sistema del CEDH, el papel subsidiario del mecanismo del Convenio implica, en primer lugar, una relación procesal entre las autoridades nacionales responsables de aplicar el Convenio y decidir las cuestiones que se le presenten de derechos humanos a la luz de éste, y, por otro lado, las instituciones del Convenio, en particular, el Tribunal de Estrasburgo. No se limita al respeto al principio general de derecho internacional procesal que impone la exigencia de agotamiento de los recursos internos antes de acudir a la instancia internacional (Artículo 35.1 CEDH), sino de

\footnotetext{
49 GREER, Steven, The Margin of Appreciation: Interpretation and Discretion Under the European Convention on Human Rights, Human Rights Files no 17, Council of Europe Publishing, Estrasburgo, julio 2000, p. 5.

50 Handyside vs. Reino Unido, §48.
}

algo sustancial: el respeto al ethos de cada comunidad política por el juez internacional. Puede comprenderse bien a lo que nos referimos comentando el inicialmente desdichado caso Lautsi vs Italia, también Ilamado "del crucifijo" en las escuelas públicas italianas. En tal caso, una madre, ciudadana finlandesa e italiana, reclamó la retirada de los crucifijos de las clases de la escuela pública italiana a la que asistían sus hijos por considerarlo un símbolo de adoctrinamiento religioso, petición que fue unánimemente aceptada por los siete jueces de la Sección 2a del Tribunal Europeo en su sentencia de 3 de noviembre de 2009. Tal decisión originó una conmoción mundial: algunos Estados Parte en el Convenio reaccionaron exigiendo al Tribunal el respeto del principio de subsidiariedad. ${ }^{51}$ La defensa del caso que hizo ante la Gran Sala del Tribunal de Estrasburgo el profesor de la Universidad de Nueva York Joseph Weiler -portando su kipá judía- fue exitosa y la decisión fue revertida. ${ }^{52}$ Merece la pena citar algún pasaje del voto particular concurrente del Juez maltés Bonello -una auténtica joya judicial por su claridad, solidez argumentativa y estilo literario-:

"Un tribunal de derechos humanos no puede permitirse padecer de Alzheimer histórico. No tiene derecho a ignorar la continuidad cultural del flujo de una nación a través del tiempo, ni a dejar de lado lo que, a lo largo de los siglos, ha servido para moldear y definir el perfil de un pueblo. No es asunto de ningún tribunal supranacional sustituir aquellas cualidades que la historia ha impreso en la identidad nacional por sus propios patrones éticos. Sobre un tribunal de derechos humanos recae la función de proteger los derechos fundamentales, pero sin ignorar que las costumbres no son caprichos pasajeros. Ellas evolucionan con el tiempo, se fraguan a lo largo de la historia en el cimiento cultural. Se convierten en definidoras, signos de suma importancia de la identidad de las naciones, tribus, religiones e individuos. Un tribunal europeo no debería ser llamado a quebrar siglos de tradición europea. Ningún tribunal, ciertamente no esta Corte, debería robar a los italianos parte de su personalidad cultural (...) Hoy, un tribunal metido en una caja de cristal a mil kilómetros de distancia se ha dedicado a prohibir de la noche a la mañana lo que ha sobrevivido a incontables generaciones. Se le ha pedido al Tribunal que sea cómplice de un grave acto de vandalismo cultural" ${ }^{53}$

51 Armenia, Bulgaria, Chipre, Rusia, Grecia, Lituania, Malta, Mónaco, Rumania y la Republica de San Marino.

$52 \mathrm{Su}$ alegato en la audiencia pública puede verse en: https://www.youtube.com/watch?v=ioylyxM-gnM

53 Lautsi y Otros vs. Italia, Gran Sala, sentencia de 18 de marzo de 2011. Vid. PUPPINCK, Grégor, "The Case of Lautsi v. Italy: A 
Desconocer el ethos histórico, cultural y religioso de un pueblo o nación no es solamente un craso e imperdonable error sino un acto que puede tener un sinfín de consecuencias indeseables. Tomando otro caso contencioso como referencia, p. ej., la apología del nacionalsocialismo, resulta incuestionable que no tiene la misma gravedad realizar tal apología nazi en Alemania -que se vio inmersa en una vorágine totalitaria causante de un indescriptible daño y dolor, particularmente a quienes fueron víctimas de la guerra, el Holocausto y el genocidio de grupos como los gitanos- o en países donde, siendo un acto reprochable, tales circunstancias históricas no tuvieron impacto directo (p. ej., en Portugal o España). Es por ello que en Alemania se estableció un modelo constitucional de democracia militante que obliga a ser leal a la Constitución, esto es, que impone la adhesión positiva a los valores constitucionales, algo que la Constitución española no exige como bien ha señalado el Tribunal Constitucional español en su sentencia 235/2007 (FJ 4ㅇ), bastando un respeto a los mismos, tal y como lo exige la ley, en particular la ley penal. ${ }^{54} \mathrm{El}$ respeto al ethos de cada Estado parte (en realidad, de la comunidad política a la que representan) es un factor sustancial que el TEDH debería tener primordialmente en cuenta en sus decisiones, a la vista de la diversidad que configura la riqueza europea. La creación de reglas homogéneas no siempre es consistente con tal diversidad, ni con el respeto debido al ethos de cada comunidad política europea. $Y$, sobre todo, en ocasiones -especialmente en temas de alto contenido moral (aborto, eutanasia, objeción de conciencia, transexualismo, úteros de alquiler, matrimonio, adopción, etc.) así como otros tantos relativos a la idiosincrasia nacional (p. ej., símbolos nacionales) el TEDH mantiene una línea no siempre consistente. En algunos casos se muestra peligrosamente activista (rozando la demiurgia), al asumir la tarea de definir un nuevo orden moral europeo sustancialmente desligado de la naturaleza humana objetivamente considerada como instancia metafísica y ética, y dotándole de una racionalidad instrumental basada en la apelación al consenso (cuando son mayoritarias) o a las tendencias sociales y legales emergentes (cuando son minoritarias). ${ }^{55}$

Synthesis", Brigham Young University Law Review, 2012, pp. 873930.

54 "En nuestro sistema - a diferencia de otros de nuestro entornono tiene cabida un modelo de 'democracia militante', esto es, un modelo en el que se imponga, no ya el respeto, sino la adhesión positiva al ordenamiento y, en primer lugar, a la Constitución (STC 48/2003, de 12 de marzo, FJ 7)." Vid., para un examen de la situación en varios países, THIEL, Markus (ed.), The 'Militant Democracy' Principle in Modern Democracies, Routledge, 2016.

\section{LA SUPERVISIÓN EUROPEA}

El margen de apreciación de los Estados va de la mano de una supervisión europea del Tribunal de Estrasburgo. Uno y otra varían en función del derecho de que se trate y las circunstancias, de modo que la doctrina del margen de apreciación del TEDH es muy casuística, ${ }^{56}$ y ha permitido que los Estados parte puedan determinar, por ejemplo, cuándo existe ofensa de los sentimientos religiosos o cuándo una publicación ha de ser calificado como obscena. La función del Tribunal no es, como sostiene el TEDH en el caso Mustafa Erdoğan y Otros vs. Turquía, tomar el lugar de las jurisdicciones nacionales competentes, sino la revisión bajo la disposición pertinente del CEDH de las decisiones por ellos adoptadas dentro de su poder de apreciación: en concreto, el Tribunal debe determinar si las razones aducidas por las autoridades nacionales para justificar una injerencia son "relevantes y suficientes" y si las medidas adoptadas son "proporcionadas al propósito legítimo buscado". ${ }^{57}$ Para ello, el Tribunal tiene que llegar a la conclusión de que las autoridades nacionales se basaron en una valoración aceptable de los hechos relevantes, y aplicaron los estándares conformes al Convenio.

La respuesta casuística no es, per se, una actitud criticable en un tribunal que ha de juzgar tan diversos casos y situaciones, en una comunidad jurídica compuesta de 47 Estados y 800 millones de personas, de tan variada realidad social, cultural, política y religiosa, y que ha ido generando una amplia jurisprudencia durante más de cincuenta años de existencia. Pero la impresión que da el Tribunal de Estrasburgo es que, más allá de la variedad de respuestas que ofrece en un contexto tan amplio y en ocasiones desmedido, sus decisiones carecen de un patrón único consistentemente aplicado, algo que se puede evidenciar particularmente en la jurisprudencia de los últimos veinte años en relación con ciertos derechos, como la vida privada, en los que la autonomía moral del individuo alcanza un mayor grado de intensidad. Así, en el caso Paradiso y Campanelli vs Italia, el TEDH constata el alto margen de apreciación de los Estados en casos relativos a "cuestiones éticamente sensibles" como el alquiler de úteros o la reproducción

55 Vid. Demir y Baykara vs. Turquía, Gran Sala, sentencia de 12 de noviembre de 2008, §§85-86.

56 Vid. ARAI-TAKAHASHI, Yutaka, The Margin of Appreciation Doctrine and the Principle of Proportionality in the Jurisprudence of the ECHR, Intersentia, 2001.

57 Mustafa Erdoğan y Otros vs. Turquía, sentencia de 27 de mayo de 2014, §35. 
artificial, pero dicho margen se reduce "cuando una importante faceta de la existencia o identidad de un individuo está en juego." 58 Pero, ¿̇i la identidad alegada del individuo es puramente arbitraria, caprichosa, o, incluso, derivada de una patología? ¿Y si tal alegación afecta directamente a la identidad de un tercero, por ejemplo, un menor, en una relación paternofilial indisponible? La nuda apelación a la identidad individual como criterio prioritario de decisión sin tener en cuenta derechos esenciales de terceros carece de razonabilidad y puede provocar serias violaciones de derechos de terceros, incluidos niños, cuyo interés superior en aplicación debe ser una consideración primordial (Art. 3 de la Convención de Naciones Unidas de Derechos del Niño de 1989). El TEDH tiende a asumir en la interpretación del derecho a la vida privada (e, incluso, a la vida familiar) la visión individualista de la persona humana, y derivadamente de los derechos humanos, sin atender a las limitaciones derivadas de la naturaleza relacional ( $y$, en particular, familiar) de la persona. El hecho de que el TEDH obligue a los Estados Parte del CEDH a reconocer en su legislación la posibilidad de una persona transexual de contraer matrimonio (con una persona de su mismo sexo genético actual), haciendo abstracción del impacto que tiene en las relaciones maritales o paternofiliales, si las hubiere, es un ejemplo de ello. ${ }^{59}$

Ciertamente, hemos asistido en estas dos últimas décadas a ciertos cambios radicales en buena parte de las sociedades europeas, en las que el relativismo ético y la exaltación, ya no de la autonomía sino de la independencia moral del individuo, se ha ido instalando progresivamente en el corazón de sus ciudadanos como hábito arraigado, en parte por la silenciosa introducción de nuevas legislaciones que han revolucionado sus hábitos y costumbres morales, en parte por la frivolidad de autoridades públicas, responsables de medios de comunicación y académicos que han dado rienda suelta a su imaginación y deseo de poder, influencia y protagonismo. Desafortunadamente, el Tribunal Europeo, o al menos una parte nada desdeñable de sus miembros, ha ido progresivamente acogiendo con benevolencia el paradigma relativista cuya normatividad pasa por el prodigado uso del "consenso europeo", concepto extraordinariamente maleable, puramente instrumental, incluso enigmático (en palabras de Douglas-Scott) ${ }^{60}$, y que ha sido utilizado con

58 Paradiso y Campanelli vs. Italia, Gran Sala, sentencia de 24 de enero de 2017, §182 y $\$ 194$.

59 Vid. Goodwin vs. Reino Unido, sentencia de 11 de julio de 2002.

60 DOUGLAS-SCOTT, Sionaidh, "Borges' Pierre Menard, Author of the Quixote and the Idea of the European Consensus", en: KAPOTAS, una racionalidad más que dudosa. Un consenso que, existente o inexistente, pretende fundar, sin indagación real y científica alguna -0 , incluso, contra la evidenciainterpretaciones del Convenio y de sus derechos que van desde la mera concreción razonable de su contenido y límites, a un descarnado activismo judicial e, incluso, más allá del bien y del mal, a la práctica de la demiurgia judicial.

\section{INTERPRETACIÓN EXTENSA, ACTIVISMO Y DEMIURGIA JUDICIALES}

Es cierto que un tratado de derechos humanos busca la garantía colectiva de los derechos reconocidos a las personas bajo la jurisdicción de los Estados Parte y la implantación de un orden objetivo de obligaciones internacionales, no condicionado ni sometido a reciprocidad, que puede calificarse de orden público. Igualmente es cierto que el tribunal autorizado para la interpretación de un tratado de derechos humanos debe considerar primordialmente tal marco en su labor hermenéutica. El problema se plantea, precisamente, cuando por vía interpretativa se modifica el propio marco interpretativo, esto es, el tribunal construye nuevos derechos sin base legal en tal instrumento internacional al que los Estados Parte prestaron su consentimiento, ni en sus tradiciones constitucionales comunes ni en la clara voluntad común de obligarse mediante otros instrumentos jurídicos internacionales relevantes para el caso de que se trate. Es lo que denunciaba el juez europeo Matscher en el caso König al acusar al TEDH de la creación de un nuevo derecho, no previsto por el CEDH ni fundado en el sistema jurídico de la mayoría de los Estados Contratantes del $\mathrm{CEDH}^{61}{ }^{61}$ Una cosa es la interpretación de lege data, y otra muy diferente la conversión de una posible interpretación de lege ferenda en derecho actual por mor de la autoridad judicial exclusivamente. No nos referimos con ello a la posibilidad de hacer una interpretación lata de una concreta disposición, mientras ésta pueda considerarse razonablemente dentro del ámbito del instrumento interpretado y con base en las tradiciones constitucionales de los Estados Parte. En tal caso, se puede concluir si se dan tales condiciones, que existe un consentimiento de los Estados que pactaron el tratado a acoger tal interpretación: así, por ejemplo, el reconocimiento del derecho a la objeción de conciencia no solamente a las

Panos y TZEVELEKOS, Vassilis (ed.), Building Consensus on European Consensus. Judicial Interpretation of Human Rights in Europe and Beyond, Cambridge University Press, 2019, p. 175

61 Voto particular disidente, König vs. Alemania, Pleno, ap. 1. 
personas físicas sino a las personas jurídicas cuando éstas poseen un ethos propio (por ejemplo, un hospital católico), reconocimiento que conlleva la tutela real y efectiva de las personas físicas que forman parte de tal institución (por ejemplo, la libertad religiosa o de conciencia de sus titulares, y los derechos de las personas que acuden al mismo por su ethos católico). ${ }^{62}$ Tampoco hablamos de explicitar un derecho ya implícitamente contenido en el instrumento internacional, de un proceso de "extracción" que presupone que en el contenido del derecho formulado expresamente se reconoce una dimensión que puede adquirir visibilidad y perfiles propios. Esta realidad, como es bien sabido, no es infrecuente en el ámbito judicial internacional y constitucional. Así, el TEDH ha declarado que la libertad de expresión del Artículo 10 CEDH incluye también la libertad académica, ${ }^{63}$ o que la libertad sindical es una forma peculiar de ejercicio de la libertad de asociación ex Artículo $11 \mathrm{CEDH} .{ }^{64} \mathrm{O}$ cuando el TC español afirma que la libertad de expresión incluye la libertad de crítica. ${ }^{65}$ Está actitud tampoco está reñida con dejarse guiar por la experiencia acumulada tras la aprobación de la norma jurídica, al modo en que el juez Holmes en el caso Missouri v. Holland afirmaba que en la Constitución no solamente hay que tener en cuenta las palabras sino la experiencia acumulada. ${ }^{66}$ Ciertamente así es, pero para "actualizar" la Constitución, la legislación, o un tratado internacional,

\footnotetext{
62 Vid. COMITÉ DE DERECHOS HUMANOS DE NACIONES UNIDAS, Comentario General no 31 sobre la índole de las obligación jurídica general impuesta a los Estados Partes en el Pacto, ap. 9 . "Los beneficiarios de los derechos reconocidos por el Pacto son personas físicas. Aunque, con excepción del artículo 1, el Pacto no menciona los derechos de las personas jurídicas o entidades o colectividades similares, muchos de los derechos reconocidos por el Pacto, como la libertad de manifestar su religión o sus creencias (art. 18), la libertad de asociación (art. 22) o los derechos de los miembros de minorías (art. 27), pueden disfrutarse en comunidad con otros. El hecho de que la competencia del Comité para recibir y examinar comunicaciones está limitada a las que presentan personas físicas o se presentan en su nombre (artículo 1 del (primer) Protocolo Facultativo) no impide que esos individuos pretendan que acciones $u$ omisiones que conciernen a las personas jurídicas y entidades similares equivalen a una violación de sus propios derechos."

${ }^{63}$ Aksu vs. Turquía, Gran Sala, sentencia de 15 de marzo de 2012; Mustafa Erdoğan y Otros vs. Turquía sentencia de 27 de mayo de 2014.

${ }^{64}$ Associated Society of Locomotive Engineers \& Firemen (ASLEF) vs. Reino Unido, sentencia de 27 de febrero de 2007, §37.

65 Sentencia 235/2007 del TC español de 7 de noviembre de 2007, FJ 4 .

${ }^{66}$ Missouri v. Holland, 252 U.S. 416, sentencia de 19 de abril de 1920: http://bit.ly/1SOev25.

67 Existe una fuerte controversia cultural entre distintas concepciones de los derechos humanos, cuya máxima expresión institucional es la representada por la Organización de Cooperación Islámica (OCl: http://bit.ly/1XBqOTB), en cuyo seno se aprobó la
}

existe un poder de enmienda o reforma que no debe obviarse, y que puede resultar necesario particularmente cuando la seriedad del asunto lo requiere. No puede dejar de reconocerse que la realidad social y las mentalidades cambian, y más en tiempos acelerados por los que los avances técnicos en un contexto de progresiva globalización. Pero ello no es óbice para respetar los procedimientos jurídicos, nacionales e internacionales, que existen en el derecho para cualquier modificación de las legislaciones y tratados.

Ciertamente, no existe una lista abstracta e intemporal de derechos humanos, entre otras cosas, porque su verdadera naturaleza no es ahistórica ${ }^{67}$. Por otro lado, los tratados internacionales de derechos humanos suelen tener una misión de tutela y no solamente de reconocimiento: algunos reconocen sola o primordialmente derechos llamados civiles o políticos, pero no socioeconómicos. Incluso en relación con ambos, ni siquiera pretenden garantizar procesalmente todos ellos: así, el Preámbulo del CEDH (párrafo 5ㅇ) afirma: "Resueltos, en cuanto Gobiernos de Estados europeos (...) a tomar las primeras medidas adecuadas para asegurar la garantía colectiva de algunos de los derechos enunciados en la Declaración Universal". ${ }^{68}$ No es infrecuente que los tratados internacionales de derechos humanos incluyan una cláusula de salvaguardia que legitime una protección más amplia de

Declaración del Cairo de derechos humanos en el Islam y el Convenio de derechos del niño en el Islam. Igualmente está en proceso de creación un Tribunal Islámico Internacional que decidiría primordialmente sobre la base de la ley islámica o sharia (Art. 27 del Proyecto de Estatuto: http://bit.ly/22CssoY). Por otro lado, cuenta Pieper que en una reunión de UNESCO sobre derechos humanos al poco de finalizar la II Guerra Mundial, el representante chino, profesor de filosofía, levantó la mano en un determinado momento para testimoniar que en su lengua no existía ni el término ni el concepto de derechos humanos. Hoy el término existe (rénquán: 人權 -chino tradicional- ó 人权 -chino simplificado-; donde "rén" 人 significa "hombre", y "quán” 權, “autoridad)", aunque el contexto cultural y la tradición histórica china necesariamente le otorgan un sentido diferente al que los "occidentales" proponemos como universal, 67 algo que probablemente vaya cambiando a medida que los chinos toman una conciencia mayor de la dignidad personal y sus derechos frente al todopoderoso y omnipresente estado.

68 El Protocolo adicional I, en su Preámbulo menciona la pretensión de los Gobiernos europeos de "tomar medidas adecuadas para asegurar la garantía colectiva de derechos y libertades distintos de los que ya figuran en el Título I" del CEDH. En igual sentido, el Preámbulo del Protocolo no 11 al CEDH. El Artículo 53 CEDH reconoce, igualmente, la posibilidad de que otros derechos humanos y libertad públicas no garantizados por el Convenio estén reconocidos por los Estados Parte. Recordemos que son ya 16 los protocolos adicionales al CEDH que se han aprobado, aunque no todos han entrado en vigor. 
tales derechos en los derechos internos de los Estados Parte: así ocurre, por ejemplo, con el Artículo 27 del Convenio de Derechos Humanos y Bioética ${ }^{69}$. También se contiene en algún caso una "Ilamada" a los Estados Parte a ampliar la protección ya otorgada por el instrumento a otros ámbitos. ${ }^{70}$

No todos los llamados "derechos humanos" encuentran reconocimiento en los tratados generales de derechos humanos. El TEDH ha afirmado que del Convenio no se pueden extraer ciertos derechos por inexistencia de base legal para ello. EI CEDH no garantiza, por ejemplo: el derecho a un estándar particular de servicios médicos o el derecho a un tratamiento médico en un país en concreto; ${ }^{71}$ el derecho a obtener un concreto estándar de vida o a obtener asistencia financiera de un Estado; ${ }^{72}$ o el derecho absoluto a una audiencia, con independencia de la naturaleza de las cuestiones, y si estas pueden o no ser resueltas adecuadamente en procedimiento escrito. ${ }^{73}$ Tampoco garantiza el citado Convenio los derechos socio-económicos en cuanto tales: por ejemplo, el derecho al trabajo, ${ }^{74}$ o un derecho general a alojamiento apropiado o a la asistencia para cubrir las necesidades básicas materiales (sólo excepcionalmente puede derivarse del Artículo 3 CEDH). ${ }^{75}$ Se excluyen de la protección del CEDH, además: el derecho de asistencia jurídica

\footnotetext{
69 "Ninguna de las disposiciones del presente Convenio deberá interpretarse en el sentido de que limite o atente contra la facultad de cada Parte para conceder una protección más amplia con respecto a las aplicaciones de la biología y la medicina que la prevista por el presente Convenio". Convenio para la protección de los derechos humanos y la dignidad del ser humano con respecto a las aplicaciones de la Biología y la Medicina (Convenio relativo a los derechos humanos y la biomedicina), hecho en Oviedo el 4 de abril de 1997. En: http://www.boe.es/buscar/doc. php?id=BOE-A-199920638

70 P. ej., Artículo 11 del Convenio europeo para el ejercicio de los derechos de los niños, Estrasburgo, 25 de enero de 1996: "Parties shall consider extending the provisions of Articles 3, 4 and 9 to proceedings affecting children before other bodies and to matters affecting children which are not the subject of proceedings."

71 Decisión sobre la admisibilidad de la demanda, Wasilewski vs. Polonia, 20 de abril de 1999.

72 Ibídem.

73 Meimanis vs. Letonia, sentencia de 21 de julio de 2015, §49.

${ }^{74}$ A. H. y J. K. vs. Chipre, sentencia de 21 de julio de 2015, §145.

75 M.S.S vs. Bélgica, Gran Sala, sentencia de 21 de enero de 2011, $\S 249$. El Convenio no obliga a un Estado miembro a dar una vivienda a una persona que viva bajo su jurisdicción ni tampoco que otorgue ayuda económica a los refugiados para permitirles tener un cierto estándar de vida.

${ }^{76}$ Anghel vs. Italia, sentencia de 25 de junio de $2013, \S 51$.

77 Vronchenko vs. Estonia, sentencia de 18 de julio de 2013, §65.

78 Sindicatul "Păstorul cel Bun" vs. Romania, Gran Sala, sentencia de 9 de julio de 2013, §137. El derecho al disenso ex Artículo 9 CEDH (libertad de pensamiento, conciencia y religión) se ejerce, dice el Tribunal, abandonando tal entidad religiosa.
}

incondicionado, en todas las disputas civiles, ${ }^{76}$ el derecho del acusado de interpelar a la víctima durante una audiencia. ${ }^{77}$ La lista es, ciertamente, mucho más amplia: no existe un derecho al disenso dentro de una entidad religiosa, ${ }^{78}$ ni un extranjero tiene derecho a entrar y residir en un concreto país. ${ }^{79}$ Tampoco existe el derecho a adquirir propiedades, ${ }^{80}$ el derecho a adoptar, ${ }^{81}$ o el derecho incondicionado del detenido a asistir a un funeral de un familiar. ${ }^{82}$ No se puede invocar con base en el Convenio ninguna actio popularis para la interpretación en abstracto de los derechos del Convenio. ${ }^{83}$ Puede observarse el carácter limitado del reconocimiento y protección que ofrece el CEDH.

El problema surge al crear ex novo por vía interpretativa una nueva realidad jurídica a la que se le dota de estatuto de derecho humano. Nos referimos al activismo judicial que extiende su capa protectora a áreas no queridas (incluso excluidas) por los artífices del instrumento internacional. El activismo llega a ser auténtica demiurgia judicial ${ }^{84}$ al pretender crear supuestos "derechos" que adolecen de defectos sustanciales de racionalidad jurídica o devalúan sustancialmente el valor moral de una institución jurídica primordial. ${ }^{85}$ La demiurgia judicial constituye una reformulación sustancial de las categorías jurídicas, de los principios, valores y reglas derivadas de la

79 Jeunnesse vs. Países Bajos, Gran Sala, sentencia de 3 de octubre de 2014, $§ 100$.

${ }^{80}$ Fabris vs. Francia, Gran Sala, sentencia de 7 de febrero de 2013, $\S 50$.

81 Frette vs. Francia, sentencia de 26 de febrero de 2002, $§ 32$.

82 Császy vs. Hungría, sentencia de 21 de octubre de 2014, $\$ 21$.

83 El Convenio no prevé "la interposición de una actio popularis para la interpretación de los derechos previstos en él ni permite a los individuos recurrir una norma establecida por el derecho interno simplemente porque consideren, sin haber sido directamente afectados por ella, que puede contravenir el Convenio." Aksu vs. Turquía, sentencia de 15 de marzo de 2012, §50.

84 El término "demiurgo" en este contexto evoca el artífice o creador, al modo platónico, que utiliza las ideas como paradigmas que han de ser realizados en el mundo. En su Timeo, Platón concibe el demiurgo como un mediador entre las ideas y lo sensible, un originador del orden cosmogónico. EGGERS LAN, Conrado, "Introducción a la lectura del Timeo, en: PLATÓN, Timeo, Ediciones Colihue, Buenos Aires, 2005, pp. 47-8. ARENDZEN, John, "Demiurge", The Catholic Encyclopedia, vol. 4, Robert Appleton Company, New York, 1908, on line: http://bit.ly/1r2TQkW.

85 Vid. TAMAYO Y SALMORÁN, Rolando, "Lenguaje del derecho y demiurgia jurídica (entre actos ilocucionarios y actos mágicos)," Estudios Jurídicos en memoria de Jorge Barrera Graf, Porrúa, México 1993, 1a ed., pp. 195-225. Versión on line: http://bit.ly/1W6RSew; ESCUDERO MORATALLA, J. Francisco, y CASAS SOLER, Gerard, "Demiurgia jurídica, lenguaje y creación de la realidad conceptual. El 'motor inmóvil' jurídico y los actos mágicos", Revista de Llengua y Dret, no 34, Barcelona, diciembre de 2000, pp. 45-66: http://bit.ly/22Cjybg. 
dignidad humana. No nos referimos simplemente a ampararse en un derecho para justificar actos contrarios a la moral, esto es, un "right to do wrong", 86 sino a lo que Ollero denomina el derecho a lo "torcido." 87 El significado primero que la Real Academia Española recoge de la palabra "torcer" es "dar vueltas a algo sobre sí mismo, de modo que tome forma helicoidal". Dos elementos conforman su definición primaria: auto-referencialidad (gira sobre sí misma) y desviación de su posición o dirección originaria, cualidades ambas que, metafóricamente, empapan las decisiones judiciales demiúrgicas que no sólo retuercen el sentido de los términos $y$, por tanto, de la realidad misma, sino que crean ideológicamente un mundo alternativo presidido en ocasiones por un "buenismo" que dramáticamente trastoca el orden natural de las cosas.

No menos iluminadoras son el resto de definiciones del término "torcer" ("mover bruscamente un miembro u otra cosa contra el orden natural") o "tergiversar" ("dar una interpretación forzada o errónea a palabras o acontecimientos"). ${ }^{88}$ Igualmente aclaradoras resultan expresiones en francés como "avoir tort" ("no tener razón") o "à tort" ("sin razón"), siendo "tort" equivalente a "daño". Decía el gobierno revolucionario francés el 23 de octubre de 1793: "Il est bien grand le tort que l'erreur ou la faiblesse de ces derniers a causé á la chose publique", refiriéndose a "quienes, por una falsa interpretación de los derechos humanos, han creído que el derecho de libertad, de propiedad les daba el de la vida y la muerte; como si se pudiera ser libre de hacer lo que perjudica a la sociedad, como si la propiedad pudiera existir sin la justicia". ${ }^{89}$ Esta es precisamente la cuestión que nos ocupa

86 Vid. WALDRON, J. "A Right to Do Wrong”, Ethics, Vol. 92, no. 1, número especial, octubre de 1981, pp. 21-39; una crítica a Waldron se puede encontrar en: GALSTON, W. A., "On the Alleged Right to Do Wrong: A Response to Waldron", Ethics, Vol. 93, no 2, enero de 1983, pp. 320-324.

87 OLLERO, A., "El derecho a lo torcido", en: PUIG, Valentín (coordinador), El fraude del buenismo, FAES, Madrid, pp. 63-78: http://bit.ly/1N7LfGY. Más increíble es lo que, según el Profesor de Harvard Richard Lazarus, está ocurriendo en el Tribunal Supremo norteamericano, en el que éste ha estado revisando sus propias decisiones casi en secreto incluso años después de dictarlas (las opiniones inicialmente publicadas se denominan "bench opinions" y "slip opinions"), con la justificación de ser sometidas a revisión formal antes de su publicación definitiva en los United States Reports. LAZARUS, Richard J., "The (Non) Finality of Supreme Court Opinions", Harvard Law Review, vol. 128, no 2, 2014, pp. 540-625: http://bit.ly/2AGvVgH

\section{6. ¿UN DERECHO A LO TORCIDO?}

Los derechos humanos no son potestades abstractas, sino exigencias estatutarias de la dignidad humana en un contexto cultural y jurídico, en el marco del bien común, del que forman parte. No puede calificarse como derecho humano ni lo intrínsecamente injusto ni aquello que no sea auténtica expresión de justicia de la genuina dignidad humana, natural y trascendente, sin subordinación a, en palabras de Tomás de Aquino, "costumbres depravadas y hábitos corrompidos" aunque sean socialmente predominantes-, que junto con las "malas persuasiones", pueden llegar a borrar los preceptos secundarios de la ley natural, que es la única y verdadera ancla de todo auténtico derecho humano. ${ }^{90}$ La ley es razón sin pasión, decía Aristóteles. Y la interpretación de la ley ha de ser, igualmente, razón sin pasión (esto es, sin pasión desordenada), de modo que el juez ha de ser, parafraseando a Tomás de Aquino, "ministrum legis". ${ }^{91}$ El juez, como dice Aristóteles, ha de preocuparse también por la ley, pero con miras al fomento de la virtud del ciudadano que permita la "amistad política", ${ }^{22}$ y no un visionario constructor de un pretendido progreso ideal y apriorísticamente concebido que utiliza sofísticamente el lenguaje para justificar lo injustificable. Resuenan en este contexto las palabras de Aristófanes en su obra Nubes, cuando Corifesa se dirige al desvergonzado Fidípides (que pretende sostener argumentalmente que es legítimo pegar a un padre y a una madre): "Es tarea tuya, oh agitador e incitador de nuevos discursos, buscar una palabra persuasiva que nos permita creer que hablas con justicia"93. Persuadir al auditorio (cualquiera que éste sea: opinión pública, elites intelectuales, poder

88 El término inglés, "tort" significa "injusticia", y procede del francés "tort," y éste del latín "tortum" ('injusticia', neutro de "tortus" -retorcido-, participio pasado de "torquere" -torcer, retorcer-). Vid. voz "tort", en HARPER, Douglas, Online Etymology Dictionary, 2015: http://www.etymonline.com "Tort Law" designa una rama del derecho de common law que protege a quien ha sufrido daño por el comportamiento injusto de otros ("tortious conduct"). GARNER, Bryan, A Dictionary of Modern Legal Usage, Oxford University Press, 2001, 2ª ed., p. 885.

89 COCHIN, A. y CHARPENTIER, Ch., Les actes du gouvernement révolutionnaire (23 août $1793-27$ juillet 1794). Recueil de documents, Tomo I (23 août-3 décembre 1793), Société d'Histoire Contemporaine, Paris, Librairie Alphonse Picard, 1920, 23 octobre, 2 brumaire, p. 307.

${ }^{90}$ S. Th., I, II, c. 94, a. 6, solución.

91 S. Th., İ-Ilae, q. 92 a. 2 ad 3.

92 ARISTÓTELES, Política III, 9, 1280 b 5-12. Vid. LLANO, Alejandro, "El humanismo cívico y sus raíces aristotélicas", Anuario Filosófico, Servicio de Publicaciones de la Universidad de Navarra, no 32, 1999, p. 450: http://bit.ly/25YYwYJ.

93 Fidípides es fanático de la hípica que endeuda a su padre Estrepsíades hasta llevarle al borde de la ruina. ARISTÓFANES, 
político, etc.) para crear apariencia de justica, para legitimar una decisión débil o nulamente fundada en la realidad del derecho en vigor, que promueve un interés particular y no el bien común social: este parece ser el afán de quienes buscan el protagonismo o el fraudulento cambio social no sólo contra legem sino contra natura.

Esa interpretación "torcida" es per se dañina, retorcidamente inconsistente con lo recto, que es el sentido y orientación de todo derecho, y constituye una tergiversación de la realidad esencial (no me refiero a la realidad epidérmica que sociológicamente puede variar y manipularse sino al orden moral de una realidad metafísicamente estructurada), emulación divina que evoca la sempiterna tentación humana de definir el bien y el mal. Pensemos en el pretendido "derecho a matarse" del suicida: si a punto de cometer suicidio, un policía le retiene con sus brazos e impide con ello que salte al vacío, ¿comete el policía un delito de coacciones? La sinrazón se manifiesta por reducción al absurdo. Es el caso igualmente de la llamada "wrongful life", expresión, ya de suyo prejuiciosa: ¿cómo se puede calificar la existencia de un ser humano como indebida por poseer el niño por nacer grandes taras genéticas y fundar en ella una demanda contra un médico al no haber podido la madre abortar por no haber sido informada de tales taras? ${ }^{94}$ Hay autores que incluso defienden el derecho de los padres a "prevenir el nacimiento" de un hijo severamente discapacitado, formulación que usa una aparente neutralidad lingüística para encubrir una grave falla ética, ${ }^{95}$ a saber: no cabe disponer intencionalmente de la vida del ser humano inocente que es, siempre y en todo caso, un bien moral inapelable. Habría más bien que hablar de un "wronful killing" para no pervertir el lenguaje ético, que es probablemente la más exitosa fórmula para manipular masivamente las conciencias de los ciudadanos, como lo atestigua el éxito de los totalitarismos socialistas del siglo XX, sean nacionales (nazismo y fascismo) o internacionales (comunismo). ${ }^{96}$

Nubes (traducción de VELÁSQUEZ, Oscar), Editorial Universitaria, Santiago de Chile, 2005, p. 107.

${ }_{94} \mathrm{El}$ asunto se ha planteado respecto de adultos con graves discapacidades que pleiteaban contra sus padres por haberles traído a este mundo, y no haber recurrido al aborto.

95 HARRIS, Cailin, "Statutory Prohibitions on Wrongful Birth Claims \& Their Dangerous Effects on Parents," Boston College Journal of Law \& Social Justice, vol. 34, no 2, mayo 2014, pp. 365-396. En: http://bit.ly/1RT8gxE.

96 Vid. KLEMPERER, Victor, LTI: la lengua del Tercer Reich,. Apuntes de un filólogo, Minúscula, Barcelona, 2012.
Pretender que la igualdad de trato entre personas, por ejemplo, no admite trato diverso en situaciones diversas (como es el caso de la equiparación jurídica entre matrimonio y lo que algunos denominan "homomonio") es un despropósito jurídico que desnaturaliza y debilita el principio de igualdad. Es tan cierto decir que sin igualdad no hay derecho como afirmar que sin distinción no hay derecho. Considerar las distinciones genuinas como obstáculos a la justicia llevará en última instancia, a la imposibilidad de sostener la primera distinción que permite la existencia del derecho, entre seres humanos y otros seres vivos. No en vano, los animalistas que, aún minoría, sostienen (con Peter Singer como vaca sagrada) que los animales, al menos los de entidad superior, tienen derechos, reivindican su propuesta teórica en términos de igualdad: la justicia se logrará, según ellos, cuando se destruya la última barrera de la discriminación entre seres: el especismo, que, según ellos, privilegia indebidamente al ser humano. ${ }^{97}$ ¿Qué se logra con todo ello? Desde luego, no humanizar al animal, sino por devaluación, animalizar el hombre. Singer lo dice expresamente: "debemos abandonar la creencia en el igual valor de la vida humana, reemplazándola por la gradación que ha de aplicarse tanto a animales como a humanos"98. El igual valor de la vida humana es, para Singer, una ficción ${ }^{99}$. Tal propuesta alternativa de gradación moral del individuo, animal o humano, estaría en función de su nivel de capacidad cognitiva, lo que indudablemente posicionaría malamente a los discapacitados mentales y a los no nacidos. Se trataría, en palabras de Singer, de expandir el "círculo moral a los animales no humanos". ${ }^{100}$ La destrucción de las distinciones legítimas llevan aparejadas siempre el retroceso de la civilización (como la falta de reconocimiento de la igualdad sustancial entre personas es de suyo una falta de civilización).

En el capítulo de lo torcido estaría en lugar preeminente la pretensión de crear un "derecho al aborto" -al modo recogido en la ley española de aborto 2010, que garantiza el acceso al mismo como prestación sanitaria

\footnotetext{
97 Especismo es, según Singer, "Ia actitud de prejuicio contra un ser por la especie a la que pertenece". En: YANCY George, "Peter Singer: On Racism, Animal Rights and Human Rights", entrevista a Peter Singer, New York Times, 27 de mayo de 2015: http://nyti.ms/1S9iQPU.

98 SINGER, Peter, "Speciesism and Moral Status", Metaphilosophy vol. 40, no 3-4, julio 2009, p. 567. En: http://www.oswego.edu/ delancey/Singer.pdf

99 SINGER, Peter, "Speciesism and Moral Status", op. cit., p. 579. 100 SINGER, Peter, The Expanding Circle. Ethics, Evolution and Moral Progress, Princeton University Press, 1981, p. 121. En: http://www.stafforini.com/txt/Singer\%20\%20The\%20expanding\%20circle.pdf
} 
(sic)- ${ }^{101}$, como si la destrucción intencional y premeditada de un ser humano inocente y en completo estado de vulnerabilidad tuviera alguna racionalidad alguna. Desgraciadamente, en la política internacional existen Estados, organizaciones internacionales y ONGs que presionan para que tales "torcidos" sean universalizados sin base alguna en instrumento jurídico internacional, acudiendo al atajo forzado de aprobar cascadas de declaraciones e instrumentos políticos internacionales pretendiendo signo de una especie de costumbre internacional cuya opinio iuris se acredita mediante la adhesión a tales principios políticos. Esta es, obiter dictum, una de las grandes tragedias del derecho internacional de los derechos humanos en la actualidad: el uso indiscriminado de textos jurídicos y no jurídicos en la interpretación judicial, como criterios que sostienen el activismo y, en algunos casos, la demiurgia judicial. ${ }^{102}$ En este contexto, el activismo judicial de tribunales como el TEDH, fomenta, además, un insano juego de intereses particulares articulados en torno a un lobbismo en numerosas ocasiones más cercano a la política y el mundo económico que a la garantía de los derechos fundamentales contenidos en el Convenio ${ }^{103}$. El juez no es progenitor de la ley y carece de potestad sobre ella, y solamente tiene competencia para servirla en la determinación de lo justo en el caso concreto. El juez ha de conservar y mantener su eficacia, dirigir y orientar la ley como medio e instrumento que es, a la determinación lo justo legal: no es una herramienta de libérrimo uso, sino que posee un "manual de instrucciones." En eso consiste, precisamente, su ministerio, en esta subordinación a la determinación de lo justo a través de la ley: no, obviamente, una subordinación mecánica y acrítica, mucho menos cuando la ley es, en realidad corruptio legis, ante la que incluso puede resistirse. Salvados estos gravísimos casos (poco comunes, por otro lado), el juez no es un "partner" del legislativo, un co-legislador, formando

101 Ley Orgánica 2/2010, de 3 de marzo, de salud sexual y reproductiva y de la interrupción voluntaria del embarazo, cuyo Artículo 18 afirma: "Los servicios públicos de salud, en el ámbito de sus respectivas competencias, aplicarán las medidas precisas para garantizar el derecho a la prestación sanitaria de la interrupción voluntaria del embarazo en los supuestos y con los requisitos establecidos en esta Ley. Esta prestación estará incluida en la cartera de servicios comunes del Sistema Nacional de Salud."

102 En España se ha llegado a pretender fundar la implantación obligatoria de las materias denominadas de Educación para la ciudadanía (una especie de ideología adoctrinadora que incorpora el laicismo, ideología de género, el relativismo moral, etc.) en una interpretación torcitera de un texto no jurídico: la Recomendación (2002)12 del Comité de Ministros a los Estados miembros relativa a la educación para la ciudadanía democrática, como si la misma obligara a España a introducir tal legislación. ambos una especie de join venture que actúa al mismo nivel en dos fases sucesivas.

El juez ha de atenerse también al sentido de la ley, lo que ocasiones puede suponer alejarse de su literalidad. Tomás de Aquino trae a colación el ejemplo del decreto que imponía pena de muerte a los extranjeros que escalaran las murallas de la ciudad por temor a que usurparan el gobierno. El Aquinate afirma la deficiencia de la ley al no prever que en el curso de una invasión enemiga algunos extranjeros pudieran escalar la muralla para defender la ciudad frente a los invasores: en tal caso, dice Tomás de Aquino, imponer la pena de muerte iría contra la justicia natural porque los benefactores no merecen la pena de muerte: "en este caso, la justicia legal debe ser dirigida por la justicia natural". ${ }^{104}$ En la determinación en el caso concreto de la justicia legal, la subordinación del juez a la ley no es servidumbre ni mucho menos esclavitud legal. El juez tiene la autonomía que le otorga no sólo posibles imprevisiones defectuosas de la ley general que no ha podido prever ciertas circunstancias y casos concretos, sino también por la indeterminación que presenta la ley. Dice Santo Tomás, "la ley no puede redactarse para incluir algunos casos particulares raros, dado que el hombre no puede prever todos los casos de tal naturaleza. Por este motivo, tras la aprobación de la ley, se necesita la decisión de los jueces mediante la cual las previsiones universales de la ley se aplican a un asunto particular. Dado que la materia de los actos humanos es indeterminada, su norma, que es la ley, debe ser indeterminada en el sentido de que no es absolutamente rígida." 105 Todo ello con sentido de equidad, dado que el juez "no es un celoso ejecutor de la ley en el peor de los sentidos, por venganza, como los que son severos en la punición", sino que "no añade más punición que la suficiente para prevenir el vicio" ${ }^{106}$ Existe, desde este punto de vista, cierto margen de decisión (y de "creatividad") ${ }^{107}$ para el juez que ayuda a

103 Vid. VAN DER VLEUTEN, Anna, "Transnational LGBTI Activism and the European Courts: Constructing the Idea of Europe", en: AYOUB, Phillip M. y PATERNOTTE, David (eds.), LGBT Activism and the Making of Europe. A Rainbow Europe?, Palgrave MacMillan, 2014, pp. 119-144; DE WAELE, Henri y VAN DER VLEUTEN, Anna, "Judicial Activism in the European Court of Justice. The case of LGBT Rights", Michigan State Journal of International Law, vol. 19, no 3, 2011, pp. 639- 666: http://bit.ly/217vg2a.

${ }^{104}$ AQUINO, Tomás de, Commentary on the Nicomachean Ethics (traducción de C. I. Litzinger, O. P.), Henry Regnery Company. Chicago, 1964, Libro V, Lección XVI, 1086. Versión on line en: http://bit.ly/1XuwvT5. 105 IDEM, 1087.

106 IDEM, 1089.

107 Pérez-Luño ha realizado una clasificación de las ocho actitudes teórico-jurídicas de la idea de creación judicial: PÉREZ LUÑO, 
la integridad de la justicia legal mediante la orientación de la justicia natural, y le permite una aplicación inteligente de la ley (como criterio pedagógico en el caso concreto que refuerza la virtud moral o limita el vicio moral), lo que no significa que pueda existir legítimamente una voluntad judicial contraria al sentido de la ley o sustituta de ella, ni mucho menos, una interpretación "torcida" de la ley. El juez al interpretar realiza una función de concretar los límites y contenido de la ley. La labor concretiva puede ser restrictiva o expansiva, reconociendo el contenido mínimo indispensable o a los casos más claros, o extendiendo la norma con un paradigma hermenéutico de optimización. Pero en ambos casos, particularmente en el segundo, se está ante lo que el Tribunal Supremo norteamericano llamaba en el caso Chevron U.S.A. vs. NRDC la "permissible construction of the statute" en los casos en los que el legislador no ha explicitado las solución a la cuestión enjuiciada. Si no hay previsión legal o es ambigua respecto de la cuestión específica, el Tribunal "no puede simplemente imponer su propia construcción de la ley". ${ }^{108}$ Ahora bien, "si un tribunal, empleando los medios ordinarios de reconstrucción de la ley [statutory construction], llega a la conclusión de que el Congreso tenía una concreta intención respecto del tema enjuiciado, tal intención es la de la ley, y debe darle efecto." ${ }^{\prime 109}$

En este sentido entendemos el rule of law como el principio según el cual somos gobernados por las leyes y no por hombres ("rule of men"), aunque éstos sean jueces. ${ }^{110}$ En el contexto de la tradición norteamericana, Thomas Paine decía en 1776 en su Common Sense: "Así como en los gobiernos absolutos el rey es la ley, así en los países libres la ley debe ser el rey; y no debe de haber otro". ${ }^{111}$ Sin embargo el peligro del "rule of men", en sus diversas formas acecha siempre a las democracias. Aristóteles, en su Política (Libro IV, 15), nos previene contra "esa forma de democracia extrema en la que el

Antonio-Enrique, "¿Qué significa juzgar?", DOXA, Cuadernos de Filosofía del Derecho no 32, 2009, pp. 151-176: http://bit.ly/1Qe9Gx5.

108 Tribunal Supremo de Estados Unidos, Chevron U.S.A. vs. NRDC, 467 U.S: 837 (1984), decisión de 25 de junio de 1984.

109 IDEM, nota 9.

110 No entraremos, en este momento, en los diferentes significados concretos y diferencias que existe entre el rule of law y otras fórmulas utilizadas en los países de tradición continental, en particular, Estado de derecho (Rechsstaat). Vid. GOSALBO-BONO, Ricardo, "The significance of the rule of law and its implications for the European Union and the United States", University of Pittsburgh Law Review, vol. 72, no 2, 2010, pp. 229-360; LOUGHLIN, Martin, The Rule of Law in European Jurisprudence, European Commission pueblo prevalece incluso sobre las leyes"112 en la que "se erige una idea falsa de libertad que contradice los verdaderos intereses de la comunidad política"113, a la que, simplemente, denomina "tiranía". ${ }^{114}$ No menos expresivo es Platón en Las Leyes, en la que el personaje ateniense, un extranjero anónimo, representante intelectual de la vida griega (que para algunos es el mismo Platón) ${ }^{115}$ afirma: "si un hombre solo, o una oligarquía o incluso una democracia, con el alma propensa a los placeres y a los deseos, con necesidad de perderse en ellos, un alma que no guarda en su interior ningún principio, sino que padece una enfermedad, incesante, insaciable y maligna, gobierna a una ciudad o a un individuo, y esa autoridad pisotea las leyes, ya no queda ningún medio de salvación". ${ }^{116}$ Y continúa: "la ruina acecha a una ciudad cuyas leyes no se respetan y carecen de eficacia; en cambio, cuando la ley impera sobre los gobernantes y éstos se someten a ellas, veo nacer allí su salvación y todos los bienes que los dioses conceden a las ciudades." 117 No hablamos de arqueología jurídica, de mera especulación o de hipótesis irreales. Recordemos que la DUDH, con la cercana experiencia de los totalitarismos del s. XX, en el Considerando tercero de su Preámbulo afirma que es "esencial que los derechos humanos sean protegidos por un régimen de Derecho ['rule of law'] ['régime de droit'], a fin de que el hombre no se vea compelido al supremo recurso de la rebelión contra la tiranía y la opresión". La tiranía o el despotismo también pueden, no lo olvidemos, ser judiciales cuando el juez, subvirtiendo la ley, se hace eco de los desordenados deseos mayoritarios, con esa opinión pública mediáticamente promulgada que, en no pocos casos, parece ser la higher law incluso en sistemas llamados constitucionales. Particularmente relevante es, en estos casos, el papel de los demagogos como ya indicara Aristóteles al referirse a la democracia en la que "no es la ley, sino la multitud, la que posee el poder

for Democracy Through Law, Estrasburgo, 29 de mayo de 2009: http://bit.ly/1xGTqPe.

111 PAINE, Thomas, Rights of Man, Common Sense and Other Political Writings (ed. por MARK, Philip), Oxford University Press, 1998, reimpresión, p. 34.

112 ARISTOTLE, The Politics and The Constitution of Athens, (ed: EVESON, Stephen), Cambridge University Press, 1996, p. 114.

113 IDEM, p. 139. Vid. JILL, Frank, “Aristotle on Constitutionalism and the Rule of Law", Theoretical Inquiries in Law, vol. 8:37, 2007, p. 46. En: http://bit.ly/1W6Hm6X.

${ }^{114}$ ARISTOTLE, The Politics and The Constitution of Athens, op.cit., Libro V, 1312b I, 5, p. 143.

115 RAMOS BOLAÑOS, José Manual, “Observaciones sobre 'Las Leyes'”, en PLATÓN, Las Leyes, Akal, Madrid, 1988, p. 18.

116 PLATÓN, Las Leyes, op.cit., p. 184.

117 IDEM, p. 186. 
supremo" ${ }^{118}$ En las democracias en las que la ley no es suprema, surgen los demagogos y deja de haber Constitución ("allá donde no rigen las leyes no hay una constitución" $)^{119}$. La ley debe poseer supremacía sobre todos, y las magistraturas deben juzgar sobre los casos particulares: solamente en tal caso hay Constitución.

El "rule of law" del que hablamos no es sólo el "rule by law", esto es, la supremacía de la ley, sino que incluye además, como sostiene Bingham, los siguientes principios que inicialmente son plenamente operativos en las jurisdicciones domésticas: accesibilidad y claridad, limitación de la discrecionalidad, igualdad ante la ley, ejercicio de buena fe y dentro de ciertos límites de las potestades (bajo control judicial), respeto a los derechos humanos, disponibilidad de procedimientos de resolución de conflictos, juicio justo y cumplimiento del derecho internacional ${ }^{120}$. Gosalbo-Bono menciona como parte del rule of law la aceptación de la división de poderes, la interdicción de la arbitrariedad del poder (lo que supone también que las leyes han de ser accesibles, claras y previsibles), la supremacía e independencia de la ley, la aplicación de la ley a todos por igual sin discriminación y el respeto a los derechos humanos universales aceptados por la comunidad internacional. ${ }^{121}$

Según Naciones Unidas, el rule of law exige que los procedimientos jurídicos, las instituciones y las normas sean conforme a los derechos fundamentales ${ }^{122}$. Todas estas consideraciones recogen la sustancia del rule of law, y en buena parte, pueden ser de directa atribución al rule of law internacional en el que opera el TEDH, incluyendo como indica el que fuera Presidente del Tribunal Internacional de Justicia, el juez Peter Tomka, la existencia de tribunales independientes e imparciales, ${ }^{123}$ y mecanismos adecuados de ejecución de las decisiones que aseguren el sometimiento a derecho. Aunque la expresión rule of law no se usa tradicionalmente en el contexto del Derecho Internacional, no existe una diferencia sustancial entre el significado primordial del rule of law en el derecho

\footnotetext{
118 Política, libro IV, parte IV.

119 Ibìdem.

120 BINGHAM, Tom, The Rule of Law, Allen Lane, 2010, p. 37 y capitulos 3-10. BINGHAM, Tom, "The Rule of Law in the International Legal Order", en: McCOQUODALE, Robert (ed.), The Rule of Law in International and Comparative Context, British Institute of International and Comparative Law, 2010, pp. 1-19.

${ }^{121}$ GOSALBO-BONO, R., "The significance of the rule of law and its implications for the European Union and the United States", University of Pittsburgh Law Review, vol. 72, no 2, 2010, p. 231.

122 NACIONES UNIDAS, Rule of Law and Human Rights: http://bit.ly/26757Ak.

123 TOMKA, Peter, "The Rule of Law and the Role of the International Court of Justice in World Affairs", Discurso inaugural
}

interno o a nivel internacional. ${ }^{124}$ Partiendo de esa base, y haciendo las extrapolaciones necesarias, el rule of law en el caso del CEDH y su Tribunal se plasmaría a nuestro juicio en: a) la supremacía de los derechos humanos en ella reconocidos y garantizados; b) el respeto por los órganos del Convenio de sus atribuciones y mandatos legalmente establecidos, incluyendo el TEDH; c) la consistencia de sus decisiones -tanto interna (coherencia de su jurisprudencia) como externa (respeto a lo establecido por el derecho internacional universal de los derechos humanos, en particular la Declaración Universal y los grandes tratados como los Pactos de Nueva York)-; d) el aseguramiento de que el CEDH "se aplique con suficiente seguridad jurídica y previsibilidad para que no se cometan arbitrariedades"; ${ }^{125}$ y e) la exclusión de toda interpretación y aplicación del CEDH arbitraria o sin fundamento legal razonable en él.

\section{INTERPRETACIÓN EVOLUTIVA DEL CONVENIO}

Como hemos indicado, los derechos humanos no son ahistóricos, como tampoco lo son los textos que los reconocen y protegen. Tampoco las sociedades son estáticas, por lo que las evoluciones sociales, mayores o menores, son una realidad histórica, que debe tenerse en cuenta en la tarea judicial. El TEDH, en su aproximación hermenéutica a tales evoluciones sociales utiliza la llamada "interpretación evolutiva del Convenio", al considerar que dicho tratado internacional es un instrumento vivo que debe ser interpretado a la luz de las condiciones presentes. ${ }^{126}$ Así por ejemplo, en el caso Goodwin sobre reconocimiento legal de la transexualidad, el TEDH da poco valor al hecho de que son pocos los Estados que han adoptado normas reconociéndola, otorgando valor decisivo a la "continua tendencia internacional a favor no sólo de una creciente aceptación social de los transexuales sino de un reconocimiento legal de la nueva identidad sexual de los transexuales tras ser operados". ${ }^{127}$ El órgano judicial europeo reconoce así un derecho que no existe

del memorial Hilding Eek, en el Centro para el Derecho Internacional y la Justicia de Estocolmo, 2 de diciembre de 2013: http://bit.ly/1VrPS1i.

124 RAOUL WALLENBERG INSTITUTE OF HUMAN RIGHTS, Rule of Law: A Guide for Politicians, Raoul Wallenberg Institute of Human Rights and Humanitarian Law and The Hague Institute for the Internationalisation of Law, 2012, p. 25: http://bit.ly/20KScQW. 125 Vid. Resolución 19/36 del Consejo de Derechos Humanos de Naciones Unidas, 19 de abril de 2012, en particular ap. 16 c): http://bit.ly/1W6GFdR.

${ }^{126}$ E. B. vs Francia, Gran Sala, sentencia de 22 de enero de 2008, $\S 92$.

127 Christine Goodwin vs. Reino Unido, sentencia de 11 de julio de 2002, §85. 
en el CEDH, ni explícita ni implícitamente, y crea un nuevo marco legal contra la tradición jurídica de los Estados parte en el CEDH, basándose en la que considera una "tendencia social". El argumento que ofrece el Tribunal como justificación a tal extralimitación es la necesidad de que la protección de los derechos sean reales y efectivos, ${ }^{128}$ y unos cada vez más altos estándares de protección de los derechos humanos que requiere una mayor firmeza en la valoración de las violaciones de los valores fundamentales de las sociedades democráticas. ${ }^{129}$ Pero, ¿según qué parámetros? Ciertos activistas considerarían una mayor protección de los derechos de la mujer la declaración del aborto como un "derecho humano", a la vista de la amplia aceptación social del mismo. Si el TEDH estuviera compuesto de suficientes jueces activistas que legitimaran tal "derecho" invocando una tendencia social sostenida, ¿sería suficiente para condenar a un Estado demandado por no reconocerlo, aunque su Constitución lo prohibiera o no lo admitiera, y la mayoría social del país lo rechazara frontalmente?

No resulta objetable el rechazo del formalismo legalista en el ámbito internacional, como tampoco lo es, a nuestro juicio, la racional y razonable apreciación de los factores sociales en la decisión judicial. Pero todo ello, sin cambio de paradigma: el juez ha de aplicar el derecho en vigor, dentro de los límites de su jurisdicción y competencia, sin abuso ni extralimitaciones. Puede ser oportuno que explicite la deficiencia o insuficiencia del derecho en vigor, apelando a la necesidad de que quien tenga la potestad para ello, enmiende una u otra. Pero ir más allá de los límites de las potestades judiciales, provoca una confusión y una incertidumbre disuasoria para los destinatarios de las decisiones judiciales. ¿Qué certeza puede dar este enfoque judicial a los potenciales Estados parte en un tratado internacional de derechos humanos respecto de las obligaciones que asumen al ratificarlo? El pretendido "progreso" en la ampliación de la protección de determinadas situaciones más allá de las obligaciones convencionales de los Estados por vía jurisprudencial, incluso de manera torcitera vulnerando el ethos de sus respectivas sociedades, constituye un poderoso incentivo para la disminución del uso del tratado internacional como vía de protección de los derechos humanos.

128 Christine Goodwin vs. Reino Unido, cit., §35.

129 Selmouni vs. Francia, sentencia de 28 de julio de 1999, §101.
Para tales fines, el TEDH ha utilizado con frecuencia la noción de "consenso europeo" de una forma que, como bien afirma Puppinck, es, en ocasiones, sorprendente: "Cuando sólo tres o cuatro Estados prohíben el aborto, el Tribunal considera que existe un amplio consenso a favor de la legalización del aborto, pero cuando cuatro Estados permiten la eutanasia, el Tribunal no ha considerado que existe un amplio consenso a favor de su prohibición, sino una ausencia de consenso a favor de su legalización" ${ }^{\prime 30}$. Algo similar se puede afirmar de la reinterpretación que hace el Tribunal Europeo de la noción de "vida familiar" ex Artículo 8 CEDH, que incluiría para dicho órgano judicial tanto la "pareja del mismo sexo que cohabita en una relación estable de hecho" como la de "una pareja de distinto sexo en similar situación"131. Es más, considera que no incluir la primera en la noción de vida familiar es algo "artificial". ¿Con qué criterio, más allá del proveniente del relativismo ético de raíz sociológica, puede el Tribunal llegar a tales conclusiones? La jurisprudencia del Tribunal es poco consistente, en ocasiones, al tratar de dar soluciones a cuestiones de alto componente ético y mediático.

Por otro lado, parece que el TEDH en su intento de avanzar hacia la reconfiguración del ethos de las sociedades europeas, sigue minusvalorando en sus razonamientos los criterios esenciales que presiden los grandes tratados y declaraciones del derecho internacional de los derechos humanos (como el Artículo 23.1 del Pacto Internacional de Derechos Civiles y Políticos, o el Artículo 10.1 del Pacto Internacional de Derechos Económicos, Sociales y Culturales) en los que la protección de la familia como grupo social fundamental responsable de la educación y cuidado de sus hijos dependientes, tiene derecho a la protección de la sociedad y el Estado. Estas disposiciones y otras tantas que gozan de consenso amplio en la comunidad internacional, han sido poco a poco diluidas en Europa, por la actitud de un Tribunal Europeo que en ocasiones se fija demasiado en cierta corrección política omnipresente y en su propia popularidad mediática. La actitud revisionista del TEDH enmendando los textos básicos universales de derechos humanos ha generado una peligrosa tendencia en países terceros, fuera de la órbita occidental, donde resultan del todo inaceptables ciertas interpretaciones ideológicas. No es sorprendente en este contexto que, en el ámbito musulmán, por ejemplo, se rechacen dichas

130 PUPPINCK, G., "Abortion and The European Convention on Human Rights", Irish Journal of Legal Studies, vol. 3 (2), 2013, pp. 168-9.

${ }^{131}$ Schalk y Kopf vs. Austria, sentencia de 24 de junio de 2010, §94. 
interpretaciones de los derechos humanos como "occidentales" o "seculares" y exista una peligrosa tendencia rupturista de la universalidad de los derechos humanos, expresada en la Declaración de El Cairo sobre Derechos Humanos en el Islam, de $1990^{132}$. Algo similar se puede decir del contexto africano, donde la dimensión familiar, social y comunitaria de la persona está explícitamente reconocida en su Carta Africana sobre los derechos humanos y de los pueblos, de $1981^{133}$.

\section{Conclusiones}

La asunción por los jueces internacionales de derechos humanos de un papel activista y creador de estándares éticos sociales que reconfiguran los principios constitutivos de los tratados que han de interpretar, subvierte el principio democrático de "gobierno por las leyes" (rule of law), traiciona el carácter subsidiario de las instancias judiciales internacionales, dificulta las relaciones sanas con las jurisdicciones nacionales, erosiona ilegítimamente las potestades soberanas de los Estados Parte en los tratados internacionales, genera una peligrosa incertidumbre e inseguridad jurídicas y altera la naturaleza del derecho convencional internacional subvirtiendo el principio de que la obligación por pacto se basa en el consentimiento. El activismo judicial de derechos humanos es un ataque a la universalidad de los derechos humanos reconocidos por la comunidad internacional, y expresados en los grandes tratados y declaraciones de referencia, entre ellos, la Declaración Universal de Derechos Humanos y los Pactos de Nueva York de 1966, al romper el consenso general aceptado en décadas precedentes. Dicho activismo es, además, un potente factor disuasorio para que los Estados asuman nuevas obligaciones jurídicas convencionales e incentiva una más amplia formulación de reservas y declaraciones a los tratados. En los casos más extremos, puede llevar a algunos Estados a retirarse del sistema de protección regional de los derechos humanos al que pertenecen. ${ }^{134}$ El respeto al principio del consentimiento del Estado en relación con las obligaciones asumidas en virtud de la ratificación de un tratado de derechos humanos, es esencial para la preservación del derecho convencional de los derechos humanos, y para evitar su disolución en

132 Vid. la resolución 2253 (2029) de la Asamblea Parlamantaria del Consejo de Europa, de 22 de enero de 2019, titulada "Sharia, the Cairo Declaration and the European Convention on Human Rights". 133 Entre otras disposiciones, en el Art. 17.3 ("La promoción y protección de la moral y de los valores tradicionales reconocidos por la comunidad serán deberes del Estado"), Art. 18.2 ("El Estado tendrá el deber de asistir a la familia, la cual custodia la moral y los un marco maleable de referencia que bien puede modificarse por procedimientos ajenos a los previstos por el propio tratado, y por tanto, fácilmente contaminables por intereses poco transparentes en atención de los estándares que deben presidir la actividad judicial en las democracias contemporáneas. Es, por ello, imperativo que los tribunales internacionales de derechos humanos respeten escrupulosamente su mandato y la integridad de los tratados que se les confían para su interpretación y aplicación, para de esta forma evitar el alto riesgo de arbitrariedad y debilitamiento del imperio del derecho que conlleva su creciente activismo y ayudar a preservar la propia universalidad de los derechos humanos reconocidos por la comunidad internacional.

\section{Bibliografía}

ARAI-TAKAHASHI, Yutaka, The Margin of Appreciation Doctrine and the Principle of Proportionality in the Jurisprudence of the ECHR, Intersentia, 2001

ARENDZEN, John, "Demiurge", The Catholic Encyclopedia, vol. 4, Robert Appleton Company, New York, 1908, on line: http://bit.ly/1r2TQkW

ARISTÓFANES, Nubes (traducción de VELÁSQUEZ, Oscar), Editorial Universitaria, Santiago de Chile, 2005

ARISTOTLE, The Politics and The Constitution of Athens, (Ed: EVESON, Stephen), Cambridge University Press, 1996

AQUINO, Tomás de, Commentary on the Nicomachean Ethics (traducción de C. I. Litzinger, O. P.), Henry Regnery Company. Chicago, 1964, Libro V, Lección XVI, 1086. Versión on line en: http://bit.ly/1XuwvT5

BARRETT, John Q., Arthur M. Schlesinger, Jr. - in Action, in Archives, in History, 2007: http://bit.ly/1V1sdFO. MAYER, David N., Liberty of Contract: Rediscovering a Lost Constitutional Right, Cato Institute, Washington, 2011

BERNHARDT, R., "Thoughts on the interpretation of human-rights treaties", en: MATSCHER, F. Y PETZOLD, H., Protecting Human Rights: The European Dimension. Studies in Honour of Gérard J. Wiarda, Colonia, 1988.

valores tradicionales reconocidos por la comunidad" y Art. 27.1 ("Todo individuo tendrá deberes para con su familia y sociedad, para con el Estado y otras comunidades legalmente reconocidas, así como para con la comunidad internacional".)

134 Vid. HORNE, Alexander, DAWSON, Joanna, MILLER, Vaughne y CAIRD, Jack Simson, A British Bill of Rights?, House of Common Library, Briefing Paper Number 7193, 19 de mayo de 2015. 
BINGHAM, Tom, The Rule of Law, Allen Lane, 2010, p. 37 y capitulos 3-10. BINGHAM, Tom, "The Rule of Law in the International Legal Order", en: McCOQUODALE, Robert (ed.), The Rule of Law in International and Comparative Context, British Institute of International and Comparative Law, 2010

CALABRESI, Steven G. y LAWSON, Gary, "The Rule of Law as Law of Law", Notre Dame Law Review, Vol. 90, no 2, 2014, pp. 483-504: http://ntrda.me/109rwkW.

CASTAÑO PEÑA, Jairo Andrés, "Análisis económico del activismo judicial: el caso de la Corte Constitucional colombiana", Revista Derecho del Estado, núm. 31, julio-diciembre, Bogotá, 2013, pp. 119-160: http://bit.ly/1VTs3yp.

CHOUDHRY, Sujit y HUNTER, Claire E., "Measuring Judicial Activism on the Court of Canada: A Comment on Newfoundland (Treasury Board) v. NAPE", McGill Law Journal, 2003, vol. 48, pp. 525562: http://bit.ly/22tm0kd.

COCHIN, A. y CHARPENTIER, Ch., Les actes du gouvernement révolutionnaire (23 août 1793-27 juillet 1794). Recueil de documents, Tomo I (23 août-3 décembre 1793), Société d'Histoire Contemporaine, Paris, Librairie Alphonse Picard, 1920, 23 octobre, 2 brumaire.

COMITÉ DE DERECHOS HUMANOS DE NACIONES UNIDAS, Comentario General no 16 sobre el derecho a la intimidad (Artículo 17), 1988

COUNCIL OF EUROPE, Reforming the European Convention on Human Rights. Interlaken, Izmir, Brighton and Beyond. A compilation of instruments and texts relating to the ongoing reform of the ECHR, Strasbourg, 2014: http://bit.ly/1qudcek.

COVER, Robert M., "The Origins of Judicial Activism in the Protection of Minorities", The Yale Law Journal, Vol. 91, no 7, junio 1982: http://bit.ly/109oHAu

DAHLBERG, M., "...It is not its task to act as a Court of fourth instance:' the case of the European Court of Human Rights", European Journal of Legal Studies, vol. 7 no 2, 2014, pp. 84-118: http://bit.ly/1Shhd65

DE WAELE, Henri y VAN DER VLEUTEN, Anna, "Judicial Activism in the European Court of Justice. The case of LGBT Rights", Michigan State Journal of International Law, vol. 19, no 3, 2011, pp. 639666: http://bit.ly/217vg2a

DOUGLAS-SCOTT, Sionaidh, "Borges' Pierre Menard, Author of the Quixote and the Idea of the
European Consensus", en: KAPOTAS, Panos y TZEVELEKOS, Vassilis (ed.), Building Consensus on European Consensus. Judicial Interpretation of Human Rights in Europe and Beyond, Cambridge University Press, 2019

EGGERS LAN, Conrado, "Introducción a la lectura del Timeo, en: PLATÓN, Timeo, Ediciones Colihue, Buenos Aires, 2005

ESCUDERO MORATALLA, J. Francisco, y CASAS SOLER, Gerard, "Demiurgia jurídica, lenguaje y creación de la realidad conceptual. El 'motor inmóvil' jurídico y los actos mágicos", Revista de Llengua y Dret, no 34, Barcelona, diciembre de 2000, pp. 45-66: http://bit.ly/22Cjybg

GARNER, Bryan, A Dictionary of Modern Legal Usage, Oxford University Press, 2001, 2a ed., p. 885

GOSALBO-BONO, Ricardo, "The significance of the rule of law and its implications for the European Union and the United States", University of Pittsburgh Law Review, vol. 72, no 2, 2010

GREER, Steven, The Margin of Appreciation: Interpretation and Discretion Under the European Convention on Human Rights, Human Rights Files no 17, Council of Europe Publishing, Estrasburgo, julio 2000, p. 5.

HARPER, Douglas, Online Etymology Dictionary, 2015: http://www.etymonline.com

HARRIS, Cailin, "Statutory Prohibitions on Wrongful Birth Claims \& Their Dangerous Effects on Parents," Boston College Journal of Law \& Social Justice, vol. 34, no 2, mayo 2014, pp. 365-396. En: http://bit.ly/1RT8gxE

HELLMAN, Arthur D., "Judicial Activism: The Good, the Bad, and the Ugly", Mississippi College Law Review, Vol. 21, 2002, p. 253: http://bit.ly/1V1uaBc

HORNE, Alexander, DAWSON, Joanna, MILLER, Vaughne y CAIRD, Jack Simson, A British Bill of Rights? House of Common Library, Briefing Paper Number 7193, 19 de mayo de 2015

KMIEC, Keenan D., "The Origin and Current Meanings of Judicial Activism", California Law Review vol. 92, no 5, octubre 2004, p. 1.446: http://bit.ly/1qoJIIE

KLEMPERER, Victor, LTI: la lengua del Tercer Reich. Apuntes de un filólogo, Minúscula, Barcelona, 2012

LAZARUS, Richard J., "The (Non) Finality of Supreme Court Opinions", Harvard Law Review, vol. 128, no 2, 2014, pp. 540-625: http://bit.ly/2AGVVgH

LLANO, Alejandro, "El humanismo cívico y sus raíces aristotélicas", Anuario Filosófico, Servicio de 
Publicaciones de la Universidad de Navarra, no 32, 1999, en: http://bit.ly/25YYwYJ

LOPEMAN, Charles S., The Activist Advocate: Policy Making in State Supreme Courts, Greenwood, 1999.

LOUGHLIN, Martin, The Rule of Law in European Jurisprudence, European Commission for Democracy Through Law, Estrasburgo, 29 de mayo de 2009: http://bit.ly/1xGTqPe

MCCRUDDEN, Christopher, "Using Comparative Reasoning in Human Rights Adjudication: The Court of Justice of the European Union and the European Court of Human Rights Compared", 15 (2012-13), Cambridge Yearbook of European Legal Studies vol. 15, 2012-2013, Hart Publishing, 2013

NACIONES UNIDAS, Definiciones de términos fundamentales en la Colección de Tratados de las Naciones Unidas, 2011: http://bit.ly/1Mtjglb

OLLERO, A., "El derecho a lo torcido", en: PUIG, Valentín (coordinador), El fraude del buenismo, FAES, Madrid, pp. 63-78: http://bit.ly/1N7LfGY

PAINE, Thomas, Rights of Man, Common Sense and Other Political Writings (ed. por MARK, Philip), Oxford University Press, 1998

PÉREZ LUÑO, Antonio-Enrique, "¿Qué significa juzgar?", DOXA, Cuadernos de Filosofía del Derecho no 32, 2009, pp. 151-176: http://bit.ly/1Qe9Gx5

PUPPINCK, G., "Abortion and The European Convention on Human Rights", Irish Journal of Legal Studies, vol. 3 (2), 2013

PUPPINCK, Grégor, "The Case of Lautsi v. Italy: A Synthesis", Brigham Young University Law Review, 2012, pp. 873-930.

RAMOS BOLAÑOS, José Manual, "Observaciones sobre 'Las Leyes', en PLATÓN, Las Leyes, Akal, Madrid, 1988

RAOUL WALLENBERG INSTITUTE OF HUMAN RIGHTS, Rule of Law: A Guide for Politicians, Raoul Wallenberg Institute of Human Rights and Humanitarian Law and The Hague Institute for the Internationalisation of Law, 2012, p. 25: http://bit.ly/20KScQW

Resolución 19/36 del Consejo de Derechos Humanos de Naciones Unidas, 19 de abril de 2012, http://bit.ly/1W6GFdR

RUIZ SOROA, José María, “¿Reglas o principios?”, El País, 8 julio 2013: http://bit.ly/1Mvu2XX

SINGER, Peter, "Speciesism and Moral Status", Metaphilosophy vol. 40, no 3-4, julio 2009, en: http://www.oswego.edu/ delancey/Singer.pdf
SINGER, Peter, The Expanding Circle. Ethics, Evolution and Moral Progress, Princeton University Press, 1981, en:

http://www.stafforini.com/txt/Singer\%20\%20The\%20expanding\%20circle.pdf

TAMAYO Y SALMORÁN, Rolando, "Lenguaje del derecho y demiurgia jurídica (entre actos ilocucionarios y actos mágicos)," Estudios Jurídicos en memoria de Jorge Barrera Graf, Porrúa, México 1993, 1a ed., pp. 195-225. Versión on line: http://bit.ly/1W6RSew

THIEL, Markus (ed.), The 'Militant Democracy' Principle in Modern Democracies, Routledge, 2016.

TOMKA, Peter, "The Rule of Law and the Role of the International Court of Justice in World Affairs", Discurso inaugural del memorial Hilding Eek, en el Centro para el Derecho Internacional y la Justicia de Estocolmo, 2 de diciembre de 2013: http://bit.ly/1VrPS1i

VAN DER VLEUTEN, Anna, "Transnational LGBTI Activism and the European Courts: Constructing the Idea of Europe", en: AYOUB, Phillip M. y PATERNOTTE, David (eds.), LGBT Activism and the Making of Europe. A Rainbow Europe?, Palgrave MacMillan, 2014

WALDRON, J. "A Right to Do Wrong", Ethics, Vol. 92, no. 1, número especial, octubre de 1981, pp. 21-39; una crítica a Waldron se puede encontrar en: GALSTON, W. A., "On the Alleged Right to Do Wrong: A Response to Waldron", Ethics, Vol. 93, no 2, enero de 1983

YANCY George, "Peter Singer: On Racism, Animal Rights and Human Rights", entrevista a Peter Singer, New York Times, 27 de mayo de 2015: http://nyti.ms/159iQPU

\section{Jurisprudencia}

Paradiso y Campanelli vs. Italia, Gran Sala, sentencia de 24 de enero de 2017

Meimanis vs. Letonia, sentencia de 21 de julio de 2015 A. H. y J. K. vs. Chipre, sentencia de 21 de julio de 2015 Obergefell v. Hodges, 26 de junio de 2015: http://bit.ly/1MFsGE3

Császy vs. Hungría, sentencia de 21 de octubre de 2014 Jeunnesse vs. Países Bajos, Gran Sala, sentencia de 3 de octubre de 2014

Mustafa Erdoğan y Otros vs. Turquía, sentencia de 27 de mayo de 2014.

Chipre vs. Turquía, Gran Sala, sentencia de 12 de mayo de 2014

Glien vs. Alemania, 28 de noviembre de 2013 
Del Río Prada vs. España, Gran Sala, sentencia de 21 de octubre de 2013

Vronchenko vs. Estonia, sentencia de 18 de julio de 2013

Sindicatul "Păstorul cel Bun" vs. Romania, Gran Sala, sentencia de 9 de julio de 2013

Anghel vs. Italia, sentencia de 25 de junio de 2013

Fabris vs. Francia, Gran Sala, sentencia de 7 de febrero de 2013

Globa vs. Ucrania, sentencia de 5 de julio de 2012

Aksu vs. Turquía, sentencia de 15 de marzo de 2012

Lautsi y Otros vs. Italia, Gran Sala, sentencia de 18 de marzo de 2011

M.S.S vs. Bélgica, Gran Sala, sentencia de 21 de enero de 2011

Schalk y Kopf vs. Austria, sentencia de 24 de junio de 2010

Depalle vs. Francia, Gran Sala, sentencia de 29 de marzo de 2010

Demir y Baykara vs. Turquía, Gran Sala, sentencia de 12 de noviembre de 2008

Saadi vs. Italia, sentencia de 28 de febrero de 2008

E. B. vs Francia, Gran Sala, sentencia de 22 de enero de 2008

Associated Society of Locomotive Engineers \& Firemen (ASLEF) vs. Reino Unido, sentencia de 27 de febrero de 2007

TC español, Sentencia 235/2007 de 7 de noviembre de 2007

Bolat vs. Rusia, sentencia de 5 de octubre de 2006

Bosphorus Hava Yolları Turizm ve Ticaret Anonim Şirketi vs. Irlanda, Gran Sala, sentencia de 30 de junio de 2005: http://bit.ly/1W2kg1e
Corte Interamericana de Derechos Humanos, sentencia en el caso Caesar versus Trinidad y Tobago, de 11 de marzo de 2005

Perez vs. Francia, Gran Sala, sentencia de 12 de febrero de 2004

Lawrence v. Texas, 539 U.S. 558, sentencia de 26 de junio de 2003: http://bit.ly/1ar3LzM.

Hammern vs. Noruega, 11 de febrero de 2003

Goodwin vs. Reino Unido, sentencia de 11 de julio de 2002.

Frette vs. Francia, sentencia de 26 de febrero de 2002

E. K. vs. Turquía, sentencia de 7 de febrero de 2002

Selmouni vs. Francia, sentencia de 28 de julio de 1999

Waite y Kennedy vs. Alemania, sentencia de 18 de febrero de 1999

García Ruiz vs. España, sentencia de 21 de enero de 1999

Osman vs. Reino Unido, sentencia de 28 de octubre de 1998

Loizidou vs. Turquía (objeciones preliminares), sentencia de 23 de marzo de 1995, http://bit.ly/26598pd

Tribunal Supremo de Estados Unidos, Chevron U.S.A. vs. NRDC, 467 U.S: 837 (1984), decisión de 25 de junio de 1984

Roe v. Wade, 410 U.S. 113, sentencia de 22 de enero de 1973: http://bit.ly/1h5nErz

Griswold v. Connecticut, 381 U.S. 479, sentencia de 7 de junio de 1965: http://bit.ly/1GPiwhH

Brown v. Board of Education of Topeka, No. 1., sentencia de 17 de mayo de 1954: http://bit.ly/22wB40r

Missouri v. Holland, 252 U.S. 416, sentencia de 19 de abril de 1920: http://bit.ly/1SOev25 